\title{
Experimental and computational analysis of a pharmaceutical-grade shape memory polymer applied to the development of gastroretentive drug delivery systems
}

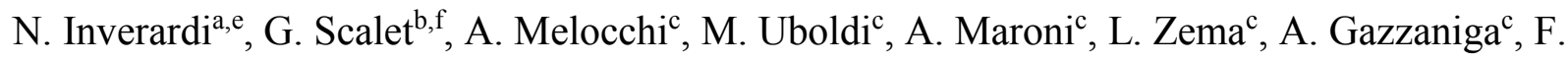

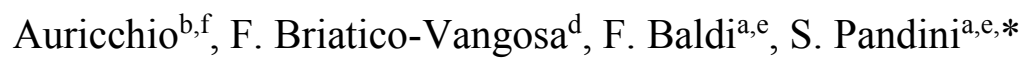

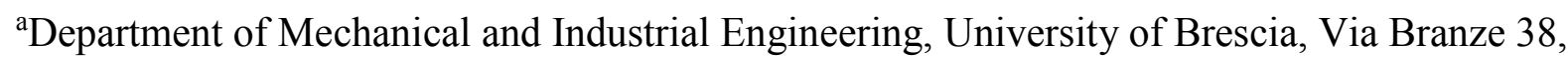
25133 Brescia, Italy

${ }^{b}$ Department of Civil Engineering and Architecture, University of Pavia, Via Ferrata 3, 27100 Pavia, Italy

${ }^{\mathrm{c}}$ Section of Pharmaceutical Technology and Legislation "Maria Edvige Sangalli", Department of Pharmaceutical Sciences, University of Milano, Via G. Colombo 71, 20133 Milano, Italy

dDepartment of Chemistry, Materials and Chemical Engineering "Giulio Natta", Politecnico di Milano, Piazza Leonardo da Vinci 32, 20133 Milano, Italy

${ }^{\mathrm{e}}$ Italian Interuniversity Consortium on Materials Science and Technology (INSTM), Research unit of Brescia, Via Branze 38, 25133 Brescia, Italy fItalian Interuniversity Consortium on Materials Science and Technology (INSTM), Research unit of Pavia, Via Ferrata 3, 27100 Pavia, Italy

*Corresponding author: stefano.pandini@unibs.it; via Branze, 3825121 Brescia, Italy +39030 3715914

\section{Abstract}

The present paper aims at developing an integrated experimental/computational approach towards the design of shape memory devices fabricated by hot-processing with potential for use as gastroretentive drug delivery systems (DDSs) and for personalized therapy if $4 D$ printing is involved. The approach was tested on a plasticized poly(vinyl alcohol) (PVA) of pharmaceutical grade, with a glass transition temperature close to that of the human body (i.e. $\left.37^{\circ} \mathrm{C}\right)$.

A comprehensive experimental analysis was conducted in order to fully characterize the PVA thermomechanical response as well as to provide the necessary data to calibrate and validate the numerical predictions, based on a thermo-viscoelastic constitutive model, implemented within a finite element framework. Particularly, a thorough thermal, mechanical, and shape memory characterization under different testing conditions and on different sample geometries was first performed. Then, a prototype 
consisting of an S-shaped device was fabricated, deformed in a temporary compact configuration and tested. Simulation results were compared with the results obtained from shape memory experiments carried out on the prototype. The proposed approach provided useful results and recommendations for the design of PVA-based shape memory DDSs.

Keywords: shape memory polymers, drug delivery systems, expandable gastroretentive drug delivery systems, constitutive modeling, poly(vinyl alcohol) 


\section{Introduction}

Shape memory polymers (SMPs) have been widely employed in the biomedical field, due to their capability to be stored and delivered to the patient in a temporary compact shape and to revert, as a consequence of the application of a triggering stimulus, to a deployed permanent shape, which should be functional to a specific need (Behl 2007). They have been mainly proposed and patented for the development of medical devices for minimally-invasive surgery, e.g. self-tightening sutures (Lendlein 2002, Lendlein 2012), self-expandable biodegradable stents (Yakacki 2007), thrombectomy devices (Small IV 2005) and embolization plugs (Bearinger 2014, Boyle 2016, Landsman 2016, Kunkel 2018). More recently, SMPs have been exploited also in the fields of tissue engineering and biomanufacturing in order to obtain both self-deploying grafts (Baker 2016, Pandey 2020) and to provide dynamic scaffolds for cell culture with a topological control based on the shape evolution of the substrate (Tseng 2013, Gong 2014, Wang 2017).

On the other hand, the use of SMPs for the development of drug delivery systems (DDSs) has been proposed only in few pioneering works (Wischke 2009, Wischke 2010, Xiao 2010, Balk 2016, Kirillova 2019).

In general, promising applications of shape memory materials in the drug delivery field are those for which a shape evolution is essential for different purposes, mainly to ensure retention of the DDS in a targeted organ so as to $i$ ) increase the bioavailability of the conveyed drug, ii) treat local diseases, and $\mathrm{iii}$ ) prolong the drug release in order to reduce the dosing frequency and consequently increase patient adherence to the therapeutic regimen (Bellinger 2016, Kirtane 2018, Babaee 2019, Maroni 2019). Thanks to the development of 4D printing concept, i.e. 3D printing of stimulus responsive materials (including SMPs), the use of SMPs has recently gained further attention in the pharmaceutical field (Firth 2018), since it enables the fabrication of devices with complex design, capable of shape-shifting over time under the application of an external non mechanical stimulus.

In this respect, also the shape memory effect exhibited by a commercially available poly(vinyl alcohol) (PVA) of pharmaceutical grade may be effective, especially in view of its safety and established use. PVA is a water-soluble synthetic polymer, commonly used as excipient in the preparation of cosmetics and medicines (JPE 2018, Ph. Eur. 10 ${ }^{\text {th }}$ Ed., USP-NF 2021). The production of high-purity pharmaceutical-grade PVA follows the rule of the current good manufacturing practices (cGMPs) and the resulting product is compliant with the requirements of various official compendia (Japanese Pharmaceutical Excipients, United States Pharmacopeia and European Pharmacopoeia), thus being suitable for the formulation of pharmaceutical products (https://www.gohsenol.com/doc_e/spcl/spcl_01/spcl_08.shtml; https://www.mchemical.co.jp/en/products/departments/mcc/emulsifier/product/1205874_8006.html). 
In particular, PVA has a very low oral acute toxicity and, when orally administered, does not accumulate in the body, being also very poorly absorbed by the gastrointestinal tract (DeMerlis 2003, Muppalaneni 2013). Furthermore, due to its chemical composition, the shape memory behavior of PVA can be triggered by the exposure to direct heating ( $\mathrm{Du} 2010 \mathrm{a}$ ), indirect heating (e.g. microwave (Du 2011, Du, H. 2015), Joule heating (Du, F.-P. 2015)), water (Du 2010b, Wang 2013, Qi 2014, Chen 2016, Fang 2017, Paonessa 2017) and, in some cases, also light (Bai 2018). The multiple actuation stimuli suitable for PVA, in addition to its biocompatibility, make this polymer a promising candidate for shape memory applications in the biomedical and pharmaceutical field involving contact with human body, where heating of even few degrees above the body temperature may cause damages to surrounding tissues (Gall 2005).

The great potential of PVA towards 4D printing technology has been recently proved by the work of Melocchi and co-authors (2019a). They demonstrated and took advantage of the shape memory effect of a commercial PVA of pharmaceutical grade for the development of an intravesical retentive drug delivery platform. The same authors have also developed prototypes of a PVA-based gastroretentive DDS via hot melt extrusion and 3D printing (Melocchi 2019b).

These were conceived with $i$ ) a permanent shape with spatial encumbrance suitable for the retention in the stomach (i.e. cylindrical and conical helices and S-shape) and ii) a temporary shape compliant with oral administration in a size 00el hard-gelatin capsule (i.e. a supercoiled helix and a paper-clip shape). In particular, gastric retention would be ensured by designing a permanent shape with at least two dimensions bigger than 11-13 mm, which is considered the average dimension of the wide open pylorus (Salessiotis 1972, Altreuter 2018). Conversely, the dimensions of the commercially available size $00 \mathrm{el}$ capsule (i.e. diameter of about $8.18 \mathrm{~mm}$ and closed length of $25.3 \mathrm{~mm}$ ) were used as reference for the development of the temporary shape. Indeed, this capsule size is one of the biggest approved, which still provides a comfortable oral administration from the patient perspective (Zhang 2015, Bellinger 2016). The recovery of the permanent shape at body temperature was then studied in simulated gastric fluid.

Despite the good results obtained, an effort still has to be made towards a comprehensive experimental and theoretical approach in order to conveniently make use of the shape memory response of pharmaceutical grade PVAs for the design of smart DDSs. More specifically, the availability of a theoretical and computational framework to speed up product development, thus avoiding costly experiments, would be highly useful.

The present work aims at exploring the possibility of supporting the design phase of DDSs relying on the shape memory response of PVA by means of a computer-aided modeling activity implemented 
within a finite element analysis framework. The prototype here investigated is the S-shaped device already presented in the companion paper by the same authors (Melocchi 2019b).

To date, several constitutive models have been proposed for the analysis and simulation of the shape memory effect of different polymers (see (Yarali 2020)), including thermo-viscoelastic (Tobushi 1997, Lin 1999, Morshedian 2005, Diani 2006, Nguyen 2008, Srivastava 2010) and phase transition (Liu 2006, Chen 2008, Wang 2009, Reese 2010, Gilormini 2012, Boatti 2016) approaches.

The three-dimensional generalized Maxwell thermo-viscoelastic model was here adopted and applied to describe the behavior of the selected PVA. The choice of dealing with such a model is motivated by the fact that it is largely employed to describe the behavior of SMPs processed by means of either traditional techniques or 4D printing (Hong 2007, Srivastava 2010, Diani 2012, Chen 2018) and its parameters can be all identified based on experimental tests. In particular, the calibration approach proposed by Diani and colleagues was here explored and discussed, which consisted in determining the time-temperature dependence of the viscoelastic properties of the polymer under investigation by using a dynamic mechanical analysis procedure without the need for shape memory cycling (Diani 2012).

A comprehensive set of experiments was carried out in order to gather the data required for the characterization of the thermo-mechanical behavior of the material and for the calibration and validation of the adopted model.

The paper is organized as follows: i) Section 2 covers all the details regarding the experimental activities and the basis of the modeling approach, $i$ ) Section 3.1 contains the thermo-mechanical data required for the model, iii) Section 3.2 describes other thermo-mechanical data useful for understanding the shape memory response of the material, iv) Section 3.3 deals with the shape memory behavior of PVA-based specimens, v) Section 3.4 illustrates the model validation and its implementation on experimental data and vi) Section 3.5 is focused on the behavior of the final prototype.

\section{Experimental}

\subsection{Materials}

A plasticized polymeric formulation was prepared by blending a PVA of a specific grade (PVA18; viscosity 18 mPas; Gohsenol ${ }^{\mathrm{TM}}$ EG 18P, Nippon Gohsei, J) with glycerol (GLY; Pharmagel, I), followed by grinding of the mixture by a blade mill and recovering the powder fraction with dimension $<250 \mu \mathrm{m}$.

The specimens were obtained by hot melt extrusion with a twin-screw extruder (Haake ${ }^{\mathrm{TM}}$ MiniLab II, Thermo Scientific, US-WI) equipped with counter-rotating screws and different dies. 
Bars and rods of $50 \mathrm{~mm}$ in length were obtained by cutting from samples extruded through a rectangular cross-section $\left(5 \times 2 \mathrm{~mm}^{2}\right)$ die and a custom-made aluminum circular $(\varnothing=1 \mathrm{~mm})$ one, respectively. Further information concerning the formulation and process parameters can be found in companion papers (bars (Melocchi 2019a); rods (Melocchi 2019b)).

\subsection{Mechanical and thermal analysis}

An extensive characterization of the mechanical and thermal behavior of PVA18 was performed in order to address the shape memory characterization of the material and understand its shape memory response, as well as to collect useful data for constitutive modeling and numerical simulations. Dynamic mechanical thermal analyses (DMTA) were performed on extruded bars by using a DMA Q800 (TA Instruments) in tensile conditions under strain control (gauge length: 10-15 mm), according to single-frequency and multiple-frequency approaches. The former consists in applying an oscillating displacement ( $10 \mu \mathrm{m}$ of amplitude) at $1 \mathrm{~Hz}$ scanning a region from $-50{ }^{\circ} \mathrm{C}$ to $200{ }^{\circ} \mathrm{C}$ with a heating rate of $3{ }^{\circ} \mathrm{C} / \mathrm{min}$. In the latter a displacement amplitude of $15 \mu \mathrm{m}$ (i.e. within the linear viscoelasticity region) was applied scanning a region from $-50{ }^{\circ} \mathrm{C}$ to $160{ }^{\circ} \mathrm{C}$ at $0.5{ }^{\circ} \mathrm{C} / \mathrm{min}$ with a sweep at a discretized set of frequencies $(100 \mathrm{~Hz}, 60 \mathrm{~Hz}, 40 \mathrm{~Hz}, 30 \mathrm{~Hz}, 20 \mathrm{~Hz}, 10 \mathrm{~Hz}, 6 \mathrm{~Hz}, 4 \mathrm{~Hz}, 3 \mathrm{~Hz}$, $2 \mathrm{~Hz}, 1 \mathrm{~Hz}, 0.6 \mathrm{~Hz}, 0.4 \mathrm{~Hz}$ ). In both cases a $0.01 \mathrm{~N}$ pre-load force was applied.

Quasi-static mechanical tests were carried out both under tensile and compressive conditions above the glass transition temperature $\left(\mathrm{T}_{\mathrm{g}}\right)$, i.e. in the rubber-like region. Tensile tests were carried out on extruded bars (gauge length: $10 \mathrm{~mm}$ ) at $60{ }^{\circ} \mathrm{C}$ by using a DMA Q800 (TA Instruments) at a ramp force of $1 \mathrm{~N} / \mathrm{min}$ up to the maximum load allowed $(18 \mathrm{~N})$. Compression tests were carried out at $60{ }^{\circ} \mathrm{C}$ by means of an electromechanical dynamometer (Instron Mod. 3366) on samples cut from the bars and tested through their thickness (cross-section: $5 \times 5 \mathrm{~mm}^{2}$ ), with a crosshead speed equal to 0.5 $\mathrm{mm} / \mathrm{min}$.

Differential Scanning Calorimetry (DSC) analyses were carried out by means of a DSC Q100 (TA Instruments) on specimen slices of about $10 \mathrm{mg}$. The tests were carried out with the use of nitrogen as purge gas and under the following thermal program: heating from $-50{ }^{\circ} \mathrm{C}$ to $240{ }^{\circ} \mathrm{C}$ at $10{ }^{\circ} \mathrm{C} / \mathrm{min}$; cooling from $240{ }^{\circ} \mathrm{C}$ to $-50{ }^{\circ} \mathrm{C}$ at $10^{\circ} \mathrm{C} / \mathrm{min}$; second heating from $-50{ }^{\circ} \mathrm{C}$ to $240{ }^{\circ} \mathrm{C}$ at $10{ }^{\circ} \mathrm{C} / \mathrm{min}$.

\subsection{Shape memory tests}

The shape memory characterization was carried out as a function of both temperature and time. The tests consisted of a two-step thermomechanical history: $i$ ) an initial so-called "programming" step by which a temporary shape was imposed, followed by ii) a subsequent recovery step. The thermo- 
mechanical histories were designed on the basis of DSC and DMTA results, which highlighted a $\mathrm{T}_{\mathrm{g}}$ of the material close to $30{ }^{\circ} \mathrm{C}$ (see Section 3.2).

Programming of the temporary shape was carried out according to the thermomechanical history described in Section 2.3.1. The recovery performance was studied under heating ramps, according to the protocol of the so-called "Thermally stimulated recovery" (TSR) (see Section 2.3.2), and as a function of time in isothermal recovery tests (see Section 2.3.3). In addition to the conventional programming history, also a programming history including a stress relaxation step was explored (see Section 2.3.4).

The tests were performed both on extruded bars and rods, using the bars for the TSR tests, since they provided a more efficient grip with the DMA fixture, and rods for the isothermal tests, as they have the same cross-section adopted for the prototypal device (see Section 2.3.5), whose recovery occurred under isothermal conditions.

Moreover, the shape memory behavior was studied on the extruded prototypal device, in order to test a real DDS, as described in Section 2.3.5.

\subsubsection{Programming}

The programming step was carried out under the following heating/cooling history, based on the $\mathrm{T}_{\mathrm{g}}$ of the material: $i$ ) heating at $60{ }^{\circ} \mathrm{C}$ (i.e. approximately $\mathrm{T}_{\mathrm{g}}+30{ }^{\circ} \mathrm{C}$ ), kept at least for 10 minutes to allow the sample to equilibrate, $i i)$ application of a specific deformation, iii) cooling well below $\mathrm{T}_{\mathrm{g}}$ (about $-20^{\circ} \mathrm{C}$ ) while keeping the imposed temporary shape, $i v$ ) storage at $-20{ }^{\circ} \mathrm{C}$ until the application of the recovery step.

Two main deformation conditions were applied in the programming step:

i) tensile deformation: a ramp force was applied at $1 \mathrm{~N} / \mathrm{min}$ through the dynamic mechanical analyzer DMAQ800 at $60{ }^{\circ} \mathrm{C}$ up to the maximum load allowed $(18 \mathrm{~N})$;

ii) U-folding: this was applied on the straight I-shaped specimens so as to obtain a U-shaped temporary shape by using a properly built fixture.

\subsubsection{Thermally Stimulated Recovery tests}

Thermally stimulated recovery (TSR) tests were carried out on previously programmed samples to investigate the shape memory behavior of the material as a function of temperature. A recovery ratio index (RI) was defined to assess the shape recovery performance.

TSR tests consisted in a controlled heating ramp. Both the definition of RI and testing conditions depend on the deformation conditions applied during programming, as here outlined: 
i) tensile deformation: the programmed bars were subjected to a heating ramp from $-20{ }^{\circ} \mathrm{C}$ to $100{ }^{\circ} \mathrm{C}$ at $0.5^{\circ} \mathrm{C} / \mathrm{min}$, under the application of a small load $(0.005 \mathrm{~N})$ to continuously monitor the specimen length. The test was carried out in the DMA Q800 under tensile conditions and the recovery index for tensile shape memory characterization $\left(\mathrm{RI}_{\text {tensile }}\right)$ was defined as follows:

$R I_{\text {tensile }}=\frac{l-l_{\text {prog }}}{l_{0}-l_{\text {prog }}}$

where $1_{0}$ is the original length of the specimen, $1_{\text {prog }}$ is the length after the programming step, and 1 is the actual length of the specimen;

ii) U-folding: the folded bars were tested in a lab oven, by placing the U-shaped sample with one half fixed to the oven plate and leaving the other half free to move. The applied heating ramp ranged from $20{ }^{\circ} \mathrm{C}$ to $180{ }^{\circ} \mathrm{C}$ at about $0.5{ }^{\circ} \mathrm{C} / \mathrm{min}$, measuring the temperature with a thermocouple placed near the sample and monitoring the recovery process with a camera (Nikon D700), acquiring 1 frame/20s (resolution of the pictures: 300 dpi x 300 dpi). The recovery index for this characterization ( $\left.\mathrm{RI}_{\text {folding }}\right)$ was defined as follows: $R I_{\text {folding }}=\frac{\alpha-\alpha_{\text {prog }}}{\alpha_{0}-\alpha_{\text {prog }}}$

where the various angles $\alpha$, all measured in rad, are defined as shown in Fig. $1 . \alpha_{0}$ is the initial angle of the specimen, $\left(\alpha_{0}=\pi\right), \alpha_{\text {prog }}$ is the angle after the programming step ( $\left.\alpha_{\text {prog }} \approx 0\right)$, and $\alpha$ is the actual angle.
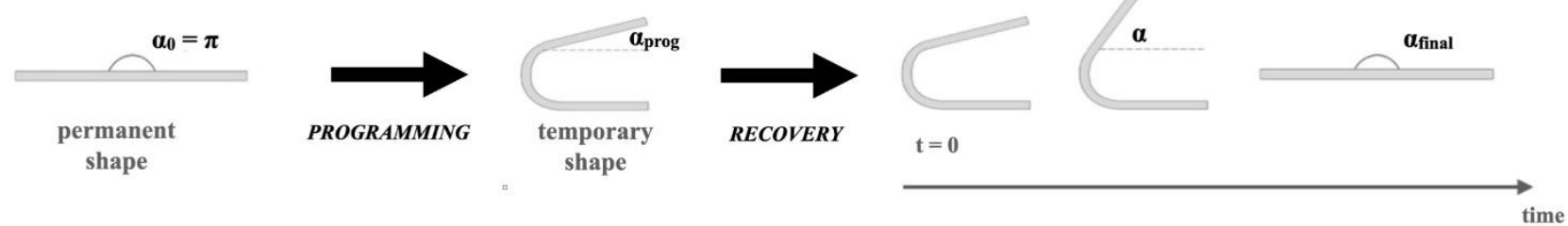

Fig. 1: Definition of the angles, $\alpha$, by a schematic description of the bar shape changes from I-shaped to U-shaped within programming, and through recovery.

\subsubsection{Isothermal recovery tests}

Samples subjected to U-folding were also subjected to isothermal recovery tests. Such tests were performed by placing programmed rod samples into a glass beaker, which was maintained at $37 \pm 1{ }^{\circ} \mathrm{C}$ by immersing it in a temperature-controlled water bath. A thermocouple was placed near the sample and temperature values were recorded during the whole test. The space in the glass was enough to allow the sample to freely change its shape. Changes in the angle $\alpha$ were recorded by means of the camera (Nikon D7000) placed above the beaker and recovery index values were calculated over time as reported in Eq. (2). 


\subsubsection{Recovery experiments on specimens subjected to prolonged constraint}

An ad hoc shape memory cycle, involving the presence of a stress relaxation period, was specifically conceived with the aim of investigating whether a prolonged constraint may affect the shape memory behavior of the specimens. The shape memory response was studied both in TSR and in isothermal tests.

TSR tests were carried out under tensile conditions in the dynamic mechanical analyzer on programmed bar-shaped specimens subjected to various relaxation times. Samples programming consisted of applying a strain equal to $10 \%$ at $60{ }^{\circ} \mathrm{C}$ and cooling to $-20{ }^{\circ} \mathrm{C}$ under fixed strain. Afterwards, while keeping the applied strain constant, a thermal equilibration at $25{ }^{\circ} \mathrm{C}$ was applied and the samples were held under this condition for increasing relaxation time $\left(t_{\text {rel }}=0\right.$ min (no relaxation), 9, 90 and $900 \mathrm{~min}$ ). Finally, the quasi-stress-free TSR protocol for tensile deformation was applied setting up a heating ramp from $25^{\circ} \mathrm{C}$ to $100{ }^{\circ} \mathrm{C}$ at $1{ }^{\circ} \mathrm{C} / \mathrm{min}$.

Isothermal tests were carried out only under bending conditions on rod specimens bent in a U-shape. The temporary U-shape in the fixture was equilibrated at room temperature (about $25^{\circ} \mathrm{C}$ ) and kept under static vacuum with silica gel for different relaxation periods $(1,7,14,21$ and 50 days) prior to the isothermal recovery. Finally, isothermal recovery was performed at $37 \pm 1{ }^{\circ} \mathrm{C}$, monitoring the recovery as described in Section 2.3.3.

\subsubsection{Shape memory tests on prototypal device}

The prototype concept consisted in developing a DDS to be manufactured in an "original" permanent configuration, to be administered in a "programmed" collapsed configuration, and able to self-expand in the patient stomach, recovering the "original" configuration upon interaction with gastric fluids at body temperature, thus preventing passage through the wide open pylorus. A schematic showing the desired working mechanism for the device is reported in Fig. 2a. The design constraints concerning gastric retention and oral administration as well as their impact on the design phase of both permanent and temporary shapes were in-depth addressed in the companion paper (Melocchi 2019b).

Starting from the extruded rods, S-shaped samples extending in the three dimensions were manufactured. Each specimen was obtained by wrapping the extruded rod, while still hot, around a purposely developed template, as shown in Fig. 2b, and removing it after 2 min cooling under pressurized air. The template was 3D-printed by a Kloner3D $240^{\circledR}$ Twin (Kloner3D, I) printer, from commercial carbonium nylon filament used as received. Further information concerning the sample and template preparation are reported in the companion paper (Melocchi 2019b). The final shape of the specimen, along with the characteristic angles to evaluate its shape evolution, are also reported in 
Fig. 2b. The resulting samples were packed in heat-sealed alufoil moisture barrier bags before being employed.

The S-shaped specimen were then programmed in a planar paper clip temporary shape, by heating them up to $60^{\circ} \mathrm{C}$. The deformed shape was achieved by inserting the specimen in a properly designed template. Deformed samples were finally cooled at $-20{ }^{\circ} \mathrm{C}$ and maintained under this temperature for at least $1 \mathrm{~h}$ before testing. The template and the specimen temporary shape are depicted in Fig. $2 \mathrm{c}$.

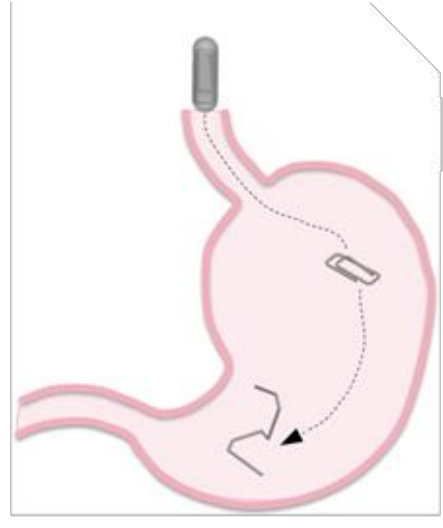

a)

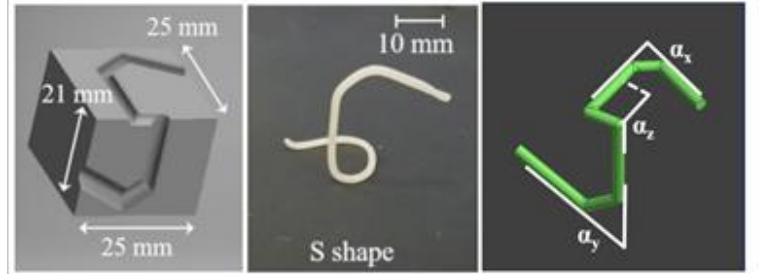

b)

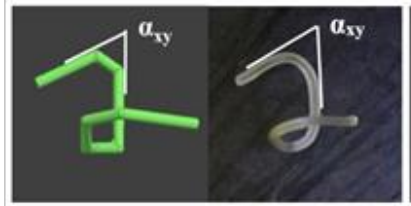

d)

$a_{y z}$

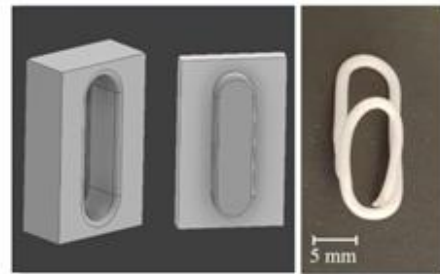

c)
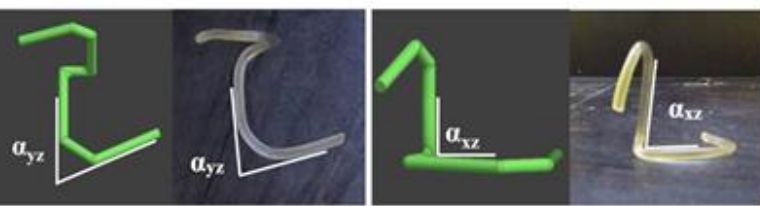

(1)

Fig. 2: a) Sketch of the shape changes underwent by the S-shaped clip from oral administration inside a capsule to retention into the stomach; b) CAD model of the template for the preparation of the original S-shaped clip, along with a photograph of the resulting sample and the relevant CAD model in which the peculiar angles defining its shape were highlighted; c) CAD model of the template for programming the temporary paper-clip shape along with a photograph of the resulting sample; $d$ ) CAD models and photographs of the samples during shape recovery in which angles used to calculate the recovery indices were highlighted.

Recovery of the original shape was studied in a thermal chamber at $37{ }^{\circ} \mathrm{C}$, placing the specimen inside a crystallization vessel and monitoring the process with two digital cameras positioned above and in front of the specimen (GoPro Hero Session, US-CA; $n=3$ ). The photographs acquired were processed using a specific software (ImageJ, US-MD).

For each of the three $\alpha$ angles, as defined in Fig. 2d, recovery indices (RIs) were calculated as follows:

i) $\quad \mathrm{RI}_{\text {axy }}=\left(\alpha_{\mathrm{xy}}-\alpha_{\mathrm{xy}, \mathrm{prog}}\right) /\left(\alpha_{\mathrm{xy}, 0}-\alpha_{\mathrm{xy}, \mathrm{prog}}\right)$

ii) $\quad \mathrm{RI}_{\alpha \mathrm{yz}}=\left(\alpha_{\mathrm{yz}}-\alpha_{\mathrm{yz}, \mathrm{prog}}\right) /\left(\alpha_{\mathrm{yz}, 0}-\alpha_{\mathrm{yz}, \mathrm{prog}}\right)$

iii) $\quad \mathrm{RI}_{\alpha \mathrm{xz}}=\left(\alpha_{\mathrm{xz}}-\alpha_{\mathrm{xz}, \mathrm{prog}}\right) /\left(\alpha_{\mathrm{xz}, 0}-\alpha_{\mathrm{xz}, \mathrm{prog}}\right)$

with $\alpha_{\mathrm{ij}, 0}$ the angle measured in the original shape, $\alpha_{\mathrm{ij}, \text { prog }}$ the angle measured in the temporary shape, and $\alpha_{\mathrm{ij}}$ is the actual angle during recovery (ij corresponding to $\mathrm{xy}, \mathrm{yz}$ and $\mathrm{xz}$ in Eq. 3, 4 and 5, respectively). 
RIs were measured on triplicates. Indeed a total of six tests was carried out, since the samples can lie on two different planes in the crystallization vessel and only two angles can be measured at a time during the recovery of the original S shape.

\subsection{Modeling and simulation}

The viscoelastic behavior of the material was captured using a three-dimensional generalized Maxwell model (Diani 2012).

According to the Abaqus Standard finite element code (Simulia, Providence, RI) nomenclature, the storage and loss modulus are defined, respectively, as follows:

$G^{\prime}(\omega)=G_{0}\left[1-\sum_{i=1}^{N} \bar{g}_{i}^{P}\right]+G_{0} \sum_{i=1}^{N} \frac{\bar{g}_{i}^{P} \tau_{i}^{2} \omega^{2}}{1+\tau_{i}^{2} \omega^{2}}$

$G^{\prime \prime}(\omega)=G_{0} \sum_{i=1}^{N} \frac{\bar{g}_{i}^{P} \tau_{i} \omega}{1+\tau_{i}^{2} \omega^{2}}$

where $\bar{g}_{i}^{P}$ and $\tau_{\mathrm{i}}$ are the Prony-parameters and $\mathrm{G}_{0}$ represents the unrelaxed modulus (i.e. the modulus at time $\mathrm{t}=0$ ), calibrated on the storage and loss modulus master curves (see Section 2.2), as proposed by Diani et al. (2012). Here we derived the Prony parameters from DMA tests performed in tensile conditions, rather than in shear mode.

The functional dependency of the time and temperature was expressed through the shift factors, $a_{T_{0}}^{T}$, obtained through the master curve construction and whose dependence on temperature was approximated by an Arrhenius-like approach, as follows:

$\ln a_{T_{0}}^{T}=\frac{E_{0}}{R}\left(\frac{1}{T}-\frac{1}{T_{0}}\right)$

where $E_{0}$, typically representing the activation energy of the relaxation process, has to be determined experimentally on the shift factor values employed for the master curve construction (Diani 2012), R is the universal gas constant, $\mathrm{T}$ is the actual temperature, and $\mathrm{T}_{0}$ is the reference temperature, both expressed as absolute temperatures.

The model was used within a finite element framework. The generalized Maxwell model, its finite strain extension (Simo 1987), and the Arrhenius equation (8) are available in Abaqus. The Prony parameters that define the master curve for small strains can be used for the finite strain model extension.

In addition, a description of the mechanical behavior of the materials in terms of an elastic response is required. In order to account for large deformation and according to experimental evidences 
reported in Section 3.1, the hyperelastic Yeoh model (Yeoh 1993) was adopted under the hypothesis of incompressible material behavior. The corresponding strain energy potential function $\mathrm{U}(\varepsilon)$ is defined as follows

$U=C_{10}\left(\bar{I}_{1}-3\right)+C_{20}\left(\bar{I}_{1}-3\right)^{2}+C_{30}\left(\bar{I}_{1}-3\right)^{3}$

where $C_{\mathrm{i} 0}$ are temperature-dependent material parameters and the first deviatoric strain invariant $\bar{I}_{1}$ is

$\bar{I}_{1}=\lambda_{1}^{2}+\lambda_{2}^{2}+\lambda_{3}^{2}$

being $\lambda_{i}$ the principal stretches.

\section{Results}

\subsection{Data generation for modeling the shape memory response}

The constitutive model employed to describe the shape memory response of the specimens is based on the viscoelastic behavior of the investigated material. In fact, the shape memory response is associated with the increase in chain mobility occurring over time and promoted by temperature, and with the entropic elasticity of the material in the rubber state as well. For this reason, the data for the model were obtained from the full master curve of the mechanical dynamical response of the material, and from the measurements of its response in the rubbery region, well above $T_{g}$.

The viscoelastic behavior described by master curves was measured starting from the multifrequency dynamic-mechanical analysis described in Section 2.2. The results are reported in Fig. 3 for what regards the storage modulus, displayed as isothermal sweeps as a function of frequency (Fig. 3a); then, the curves were mutually shifted until best superposition, by applying a frequency-temperature equivalence principle for a reference temperature, chosen as $\mathrm{T}_{0}=60^{\circ} \mathrm{C}$ (Fig. 3b). This approach was employed also for the loss modulus (Fig. $3 \mathrm{c}$ ) and $\tan \delta$ master curves construction, and it allowed to obtain a full description of the temperature dependence in terms of the shift factor versus temperature correlation (Fig. 3d). 


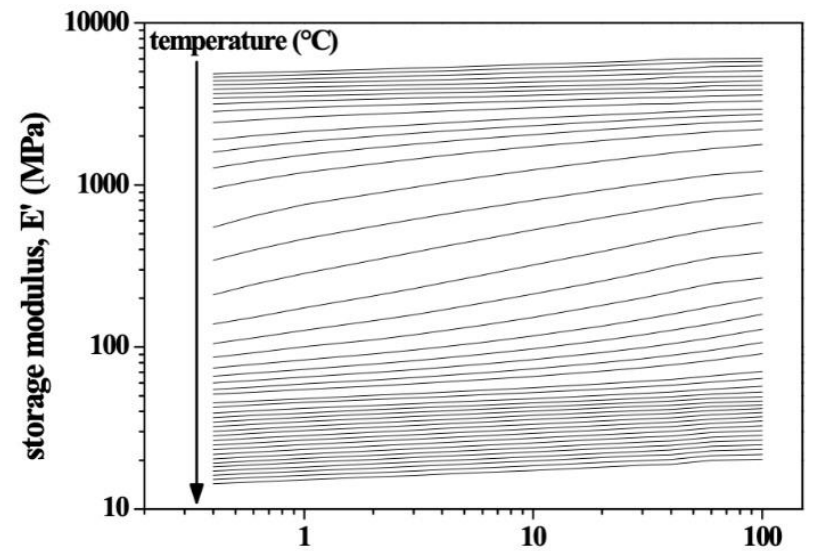

a)

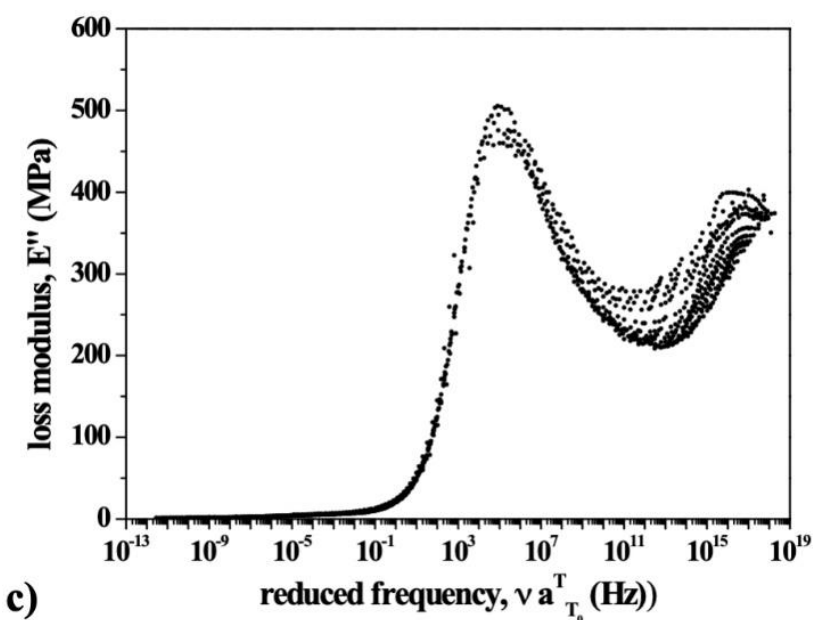

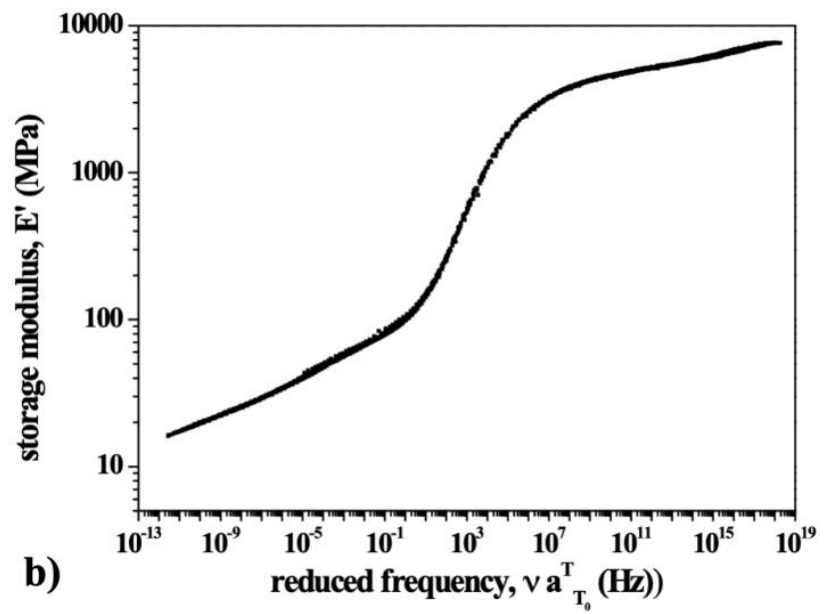

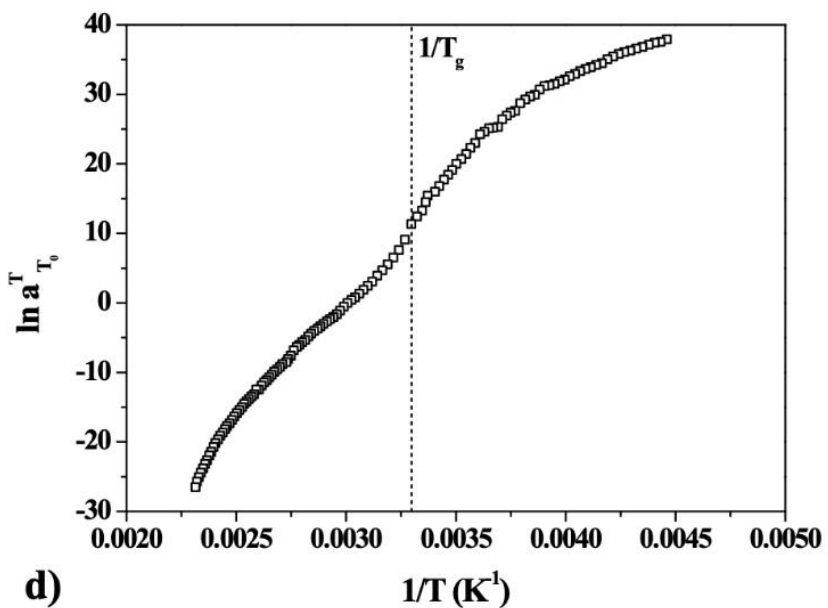

Fig. 3. a) Storage modulus as a function of frequency in isothermal segments of the multifrequency DMA test; master curve b) of the storage modulus and c) of the loss modulus as a function of reduced frequency $\left.\left(\mathrm{T}_{0}=60^{\circ} \mathrm{C}\right) ; \mathrm{d}\right)$ map of the shift factor - temperature correlation.

The storage modulus master curve showed a continuous decrease of modulus as frequency decreases. Indeed, it moved from high modulus values (about 3-7 GPa for frequency above $10^{10} \mathrm{~Hz}$ ) to values between 100 and $10 \mathrm{MPa}$ at frequencies below the relaxation one, along a continuous decreasing trend. The shift factors, plotted as a function of the inverse absolute temperature, highlighted the presence of a multiple Arrhenius dependence in the glassy region, and barely suggested a WilliamsLandel-Ferry dependence across the glass transition (on a short region between $25^{\circ} \mathrm{C}(1 / \mathrm{T}=0.00335$ $\left.\mathrm{K}^{-1}\right)$ and $\left.80{ }^{\circ} \mathrm{C}\left(1 / \mathrm{T}=0.00283 \mathrm{~K}^{-1}\right) ; 1 / \mathrm{T}_{\mathrm{g}}=0.00327 \mathrm{~K}^{-1}\right)$.

Starting from these data, an attempt to describe the relaxation modulus as a function of time was made and reported in Fig. 4 for a temperature $\mathrm{T}_{0}=25{ }^{\circ} \mathrm{C}$, under the approximation that $\mathrm{E} \simeq \mathrm{E}$ ' and that the reduced time is $\mathrm{t} / \mathrm{a}^{\mathrm{T}} \mathrm{T} 0 \simeq\left(\omega^{*} \mathrm{a}^{\mathrm{T}} \mathrm{T} 0\right)^{-1}$. 


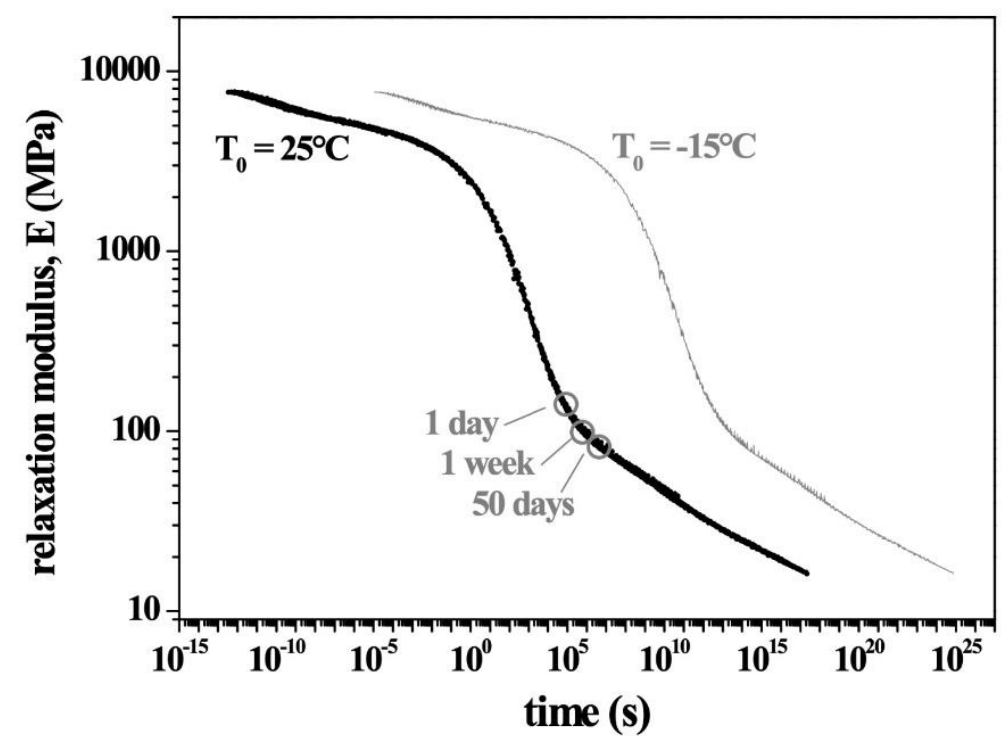

Fig. 4. Approximate relaxation modulus master curve as a function of time for a temperature $\mathrm{T}_{0}=$ $25{ }^{\circ} \mathrm{C}$, with relevant instants for the relaxation process; in gray: master curve for a temperature $\mathrm{T}_{0}=$ $-15^{\circ} \mathrm{C}$.

This representation was useful in describing the stress relaxation occurring under a fixed strain condition. The curve for $\mathrm{T}_{0}=25{ }^{\circ} \mathrm{C}$ suggested that at room temperature a large portion of the relaxation process took place in short time, so that after 1 day the end of the transition region was approached, and after 1 week the material entered its rubbery region. However, for longer times, although the material is in the relaxed state, its modulus value remained very high up to more than 50 days. Although calculated following an approximation, the results allowed to quantify the extent of the relaxation process as a function of time, and clearly suggested that, as expected, a significant decrease of modulus already occurred at relatively short times. In fact, after 1 day the modulus was reduced to about $2 \%$ of its "unrelaxed" value (i.e. the value measured at the shortest time), and after 50 days it got further reduced to about $1 \%$ of the same value. By contrast, the curve referred at $\mathrm{T}=-$ $15^{\circ} \mathrm{C}$ (i.e. a typical value for low temperature storage) suggested a significantly slower relaxation. The material was still in its glassy region at least up to 1 day, and approached the transition region at 50 days, with a modulus equal to about $2 \mathrm{GPa}$.

These findings may be important when dealing with the encapsulated gastroretentive device, pointing out that by simply storing it for very short times at room temperature, a large relaxation process may occur and this could affect the shape memory response by simultaneously better fixing the temporary folded shape and partially erasing the memory of the permanent, or undeformed, one. In fact, as the system may easily recover part of the deformation at room temperature, the presence of the constraint provided by the capsule could help prevent it. Due to its low $\mathrm{T}_{\mathrm{g}}$, PVA may undergo significant stress relaxation, whose effect on the achievement of shape recovery is not a priori known, especially 14 
following prolonged constrained conditions. For these reasons, the shape memory behavior after imposing a constraint was worthy of analysis and the results are reported in Section 3.3.

The material mechanical behavior above $\mathrm{T}_{\mathrm{g}}$ was investigated at $60{ }^{\circ} \mathrm{C}$ and the results, obtained by experiments under tensile and compression conditions (see Section 2.2), are displayed as nominal stress versus nominal strain curves in Fig. $5 \mathrm{a}$ and $5 \mathrm{~b}$, respectively. The tensile behavior was studied up to the maximum strain applied during the tensile programming of the temporary shape, due to a limited extension of the DMA crosshead. On the other hand, the compressive conditions were applied up to very high level of strain (about 70\%).
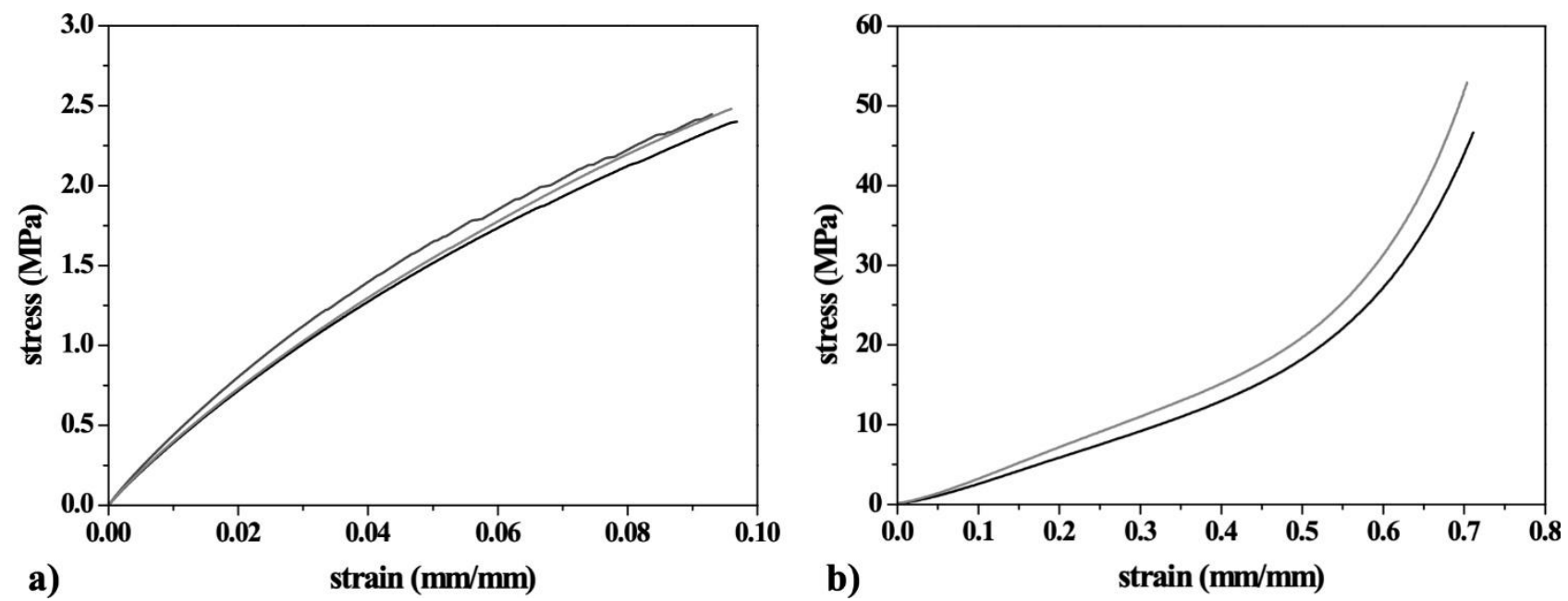

Fig. 5. Nominal stress vs. nominal strain curves at $60{ }^{\circ} \mathrm{C}$ measured in triplicates in a) tensile tests and b) compression tests.

\subsection{Characterization of the thermo-mechanical behavior}

The thermal and thermo-mechanical behavior of the material was further investigated by DSC and DMTA experiments. The DSC thermograms and storage modulus (E') curves as a function of temperature are reported in Fig. $6 \mathrm{a}$ and b, respectively. 

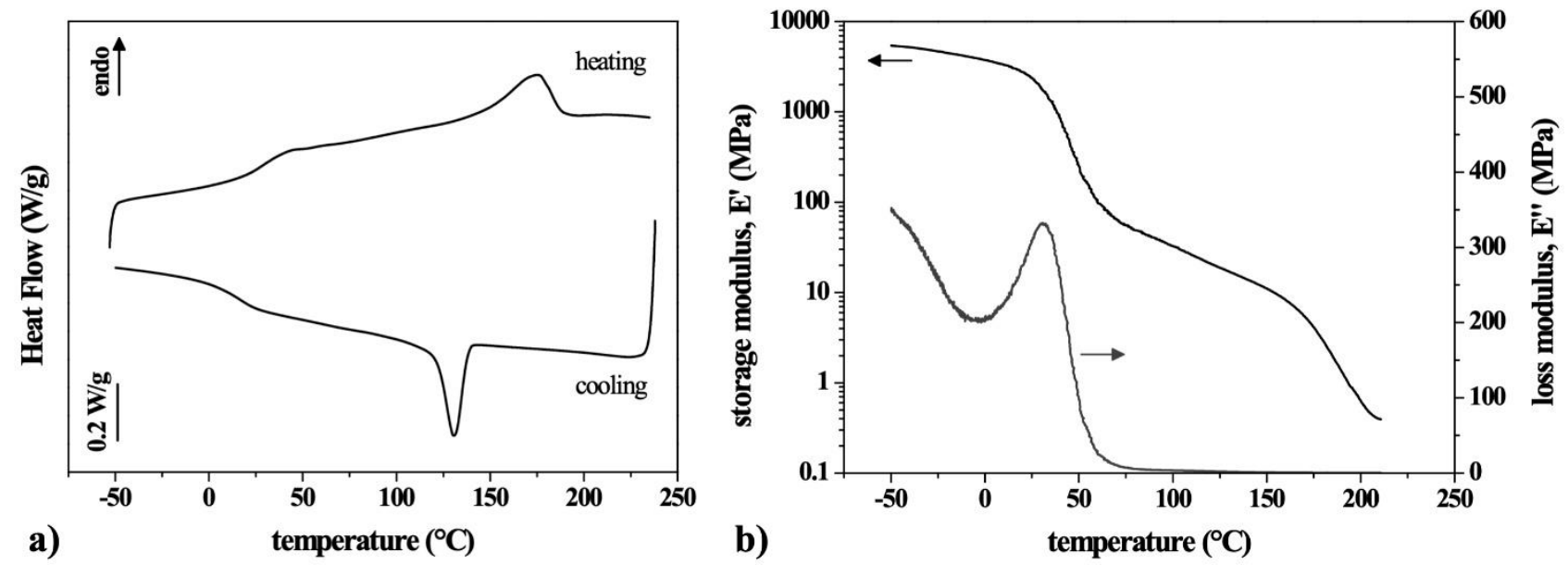

Fig. 6. a) DSC thermograms showing the cooling and second heating scan; b) DMTA curves of the storage modulus and loss modulus as a function of temperature at $1 \mathrm{~Hz}$.

In particular, in Fig. 6a the cooling and second heating scans are reported, which allowed to identify the glass transition temperature $\left(\mathrm{T}_{\mathrm{g}}\right)$, the melting temperature $\left(\mathrm{T}_{\mathrm{m}}\right)$, the crystallization temperature $\left(\mathrm{T}_{\mathrm{c}}\right)$, and the enthalpy at melting, from which it was possible to calculate the degree of crystallinity. The $T_{g}$ was identified slightly above room temperature, at about $27^{\circ} \mathrm{C}$, whereas $T_{m}$ and $T_{c}$ occurred at higher temperatures $\left(\mathrm{T}_{\mathrm{m}}=179{ }^{\circ} \mathrm{C}\right.$ and $\left.\mathrm{T}_{\mathrm{c}}=132{ }^{\circ} \mathrm{C}\right)$. This clearly confirmed that the material may manifest significant viscoelastic effects, such as stress relaxation or strain recovery, at room temperature. Conversely, its crystalline structure required temperatures well above $120{ }^{\circ} \mathrm{C}$ to be modified. By evaluating the area of the melting peak $\left(\Delta \mathrm{H}_{\mathrm{m}}=25.9 \mathrm{~J} / \mathrm{g}\right)$, the crystallinity content was quantified as about $18.7 \%$ (assuming the melting enthalpy of $100 \%$ crystalline PVA equal to 138.60 $\mathrm{J} / \mathrm{g}$ (Peppas 1976)).

Analogous consideration can be drawn from the DMTA data, thanks to which the transition region was clearly identified slightly above room temperature, and extending up to $60^{\circ} \mathrm{C}$, and $\mathrm{T}_{\mathrm{g}}$, evaluated from the peak of the loss modulus curve, is equal to $33{ }^{\circ} \mathrm{C}$.

In the thermo-mechanical characterization, also the inherent shrinkage ability, deriving from internal stresses, was taken into account. In fact, the presence of stresses, related to the extrusion processing history of the material, may lead to changes in the specimen geometry, such as axial shrinkage or flexural bending, which might disturb the measurement of the shape memory response. For this reason, freshly extruded specimens were subjected to a heating ramp in the Dynamic Mechanical Analyzer under quasi-stress-free conditions in order to measure the presence of shape variation phenomena upon heating. The results obtained are displayed in Fig. 7, where the shrinkage behavior is correlated to the deviation from an ideal base-line (dashed line in the graph), representing the thermal expansion of the specimen. The comparison between sample length and the baseline clearly 
highlighted that a significant shrinkage process may take place, and the overall shrinkage, evaluated up to $250{ }^{\circ} \mathrm{C}$, summed up to $75 \%$ of the specimen length after extrusion. However, shrinkage seemed to become a relevant effect only at temperatures above $160{ }^{\circ} \mathrm{C}$, and the magnification of the traces reported in the picture inset showed that the curve deviation onsets at about $100{ }^{\circ} \mathrm{C}$ and summed up to only $1 \%$ at about $150{ }^{\circ} \mathrm{C}$. The shrinkage effect due to processing frozen stress was thus present but should not interfere with the shape recovery process, which is known to take place across the glass transition region (Melocchi 2019a).

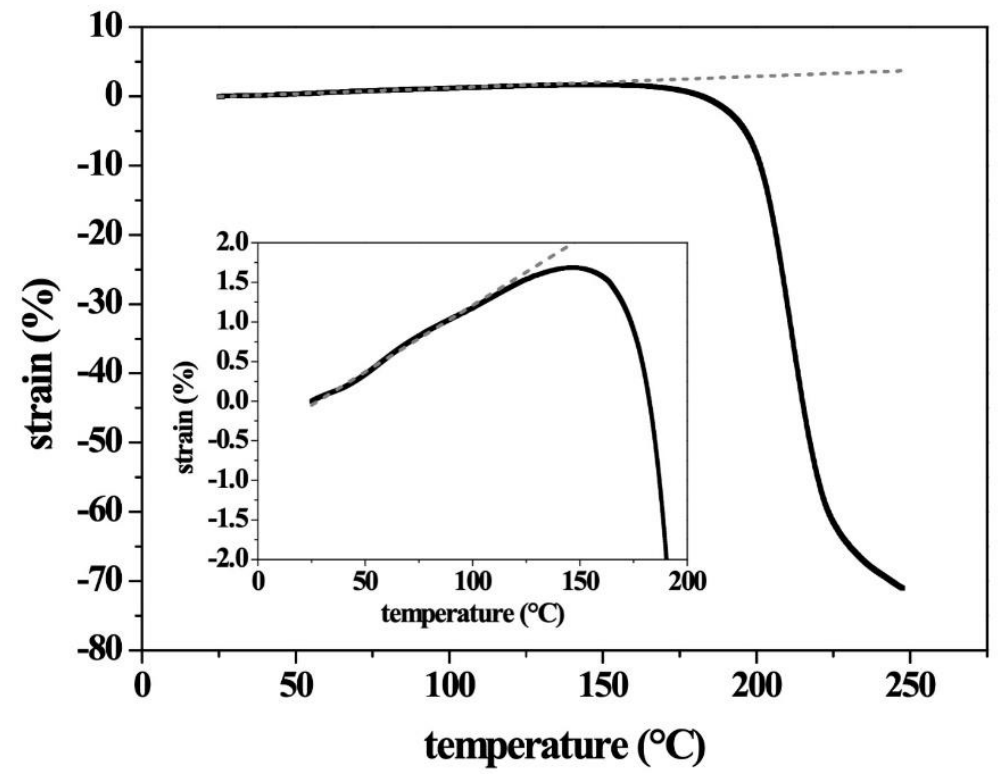

Fig. 7. Quasi-stress-free strain change due to shrinkage of the specimen along a heating ramp. The dashed line is reported as baseline representing an ideally pure thermal expansion. Inset: magnification of the shrinkage curve and of the base-line for temperatures up to $180{ }^{\circ} \mathrm{C}$.

\subsection{Characterization of the shape memory response}

The shape memory behavior was investigated through shape memory cycles, starting with the "programming" of extruded samples in a temporary shape, and continuing with recovery tests carried out in isothermal experiments or under a heating ramp, as described in Section 2.3. More in details, recovery tests triggered by a heating ramp (TSR tests) are widely used to evaluate the shape-memory performance of thermally-activated SMPs, since their activation mechanism relies on changes in macromolecular mobility occurring over a transformation temperature window (in this case, over the glass transition region). Results of the TSR tests were used to test the prediction capability of the calibrated model. Conversely, recovery tests under isothermal conditions were performed at $37^{\circ} \mathrm{C}$ to simulate the intended actuation stimulus for the ultimate DDS and quantify its recovery capability in such conditions. 
A sketch of the shape memory test carried out in tensile configuration is shown in the inset of Fig. 8a for the standard programming history. The specimen was first heated up to $60{ }^{\circ} \mathrm{C}$, then deformed up to the applied strain $\left(\varepsilon_{\text {appl }}=10 \%\right)$, cooled under fixed strain down to $-20{ }^{\circ} \mathrm{C}$, and then unloaded and subjected to a heating ramp at $0.5^{\circ} \mathrm{C} / \mathrm{min}$, during which the shape recovery occurred.

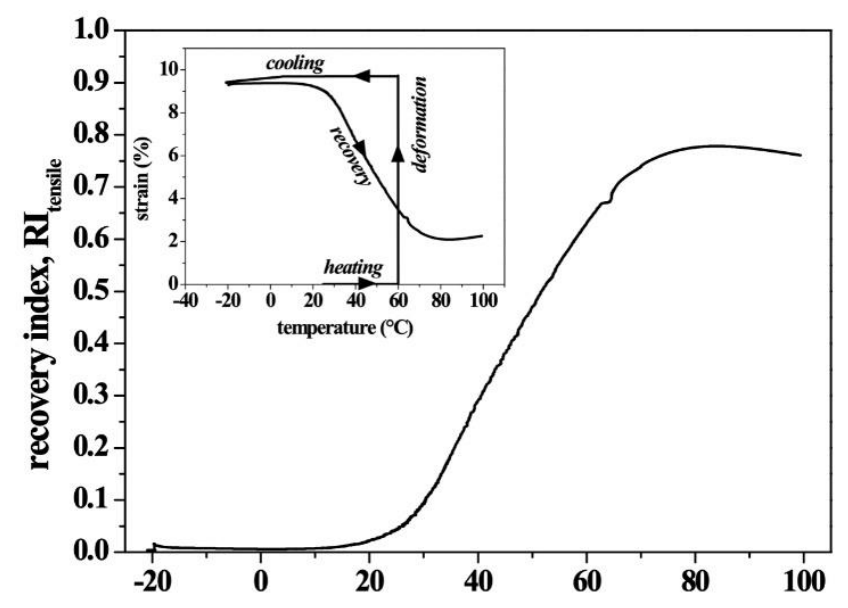

a)

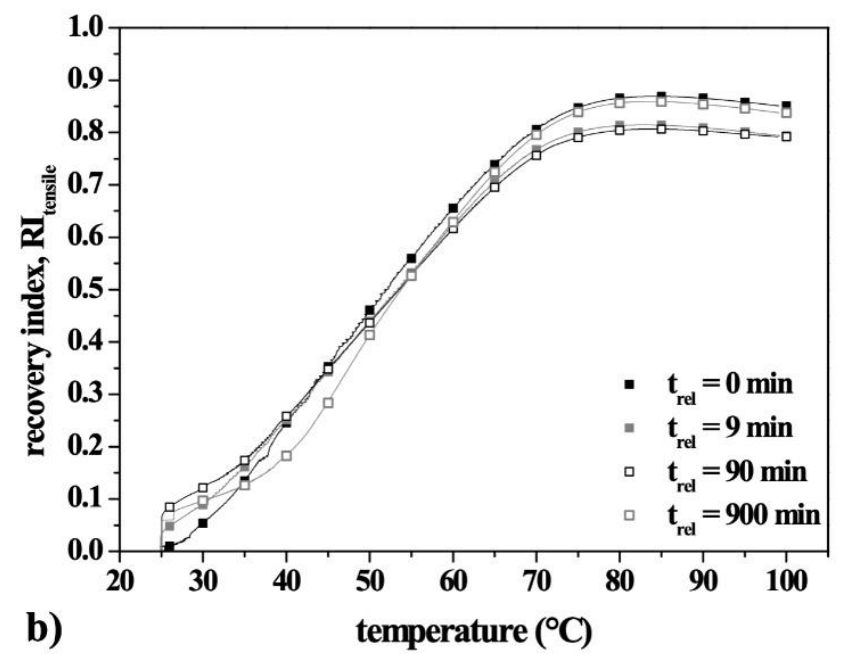

b)

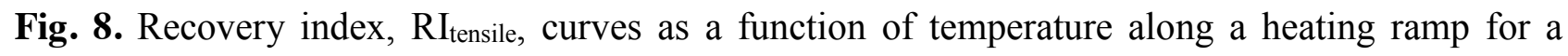
specimen subjected to recovery a) right after cooling under fixed strain and b) for various relaxation times $t_{\text {rel }}$ under fixed strain $(0,9,90$ and $900 \mathrm{~min})$. Inset of Fig. 8a: Representation of the shape programming and recovery protocol in terms of strain vs temperature.

The curve reported in Fig. 8a showed a continuous recovery of the applied strain from room temperature up to $100{ }^{\circ} \mathrm{C}$ : the recovery seemed to start at about $10{ }^{\circ} \mathrm{C}$, but gained a significant rate only above $30{ }^{\circ} \mathrm{C}$, finally leading to an almost complete $(84 \%)$ recovery of the applied strain at $80{ }^{\circ} \mathrm{C}$. The inversion of the recovery at high temperatures may be due to the concurrent thermal expansion of the sample, becoming the only dimensional change present once the recovery process is complete. The presence of an irreversible strain is often associated with the response of a semicrystalline polymer in the absence of a crosslinked structure and when heating is well below melting temperature. The curves in Fig. $8 \mathrm{~b}$ refer to specimens subjected to stress relaxation at room temperature before recovery. For all the specimens tested, the recovery took place immediately after unloading, and for those subjected to relaxation it started with a first step increment of the recovery index, representing an elastic, or short-time viscoelastic, response. The extent of such instantaneous recovery became higher as the time under relaxation increased. This finding highlighted that, during the relaxation step, the specimen, trying to recover but being forced under fixed strain, increased its internal energy, finally leading to such an early sharp recovery. After this early step, the subsequent recovery seemed 
to occur at an initial lower rate for samples that were kept under relaxation for longer times, but a similar increasing trend was found above $50^{\circ} \mathrm{C}$, and the maximum recovery slightly varied, with no dependence on relaxation history, between $81 \%$ and $87 \%$. Based on the results obtained, the relaxation step at room temperature for a time scale in the order of one day seemed not to alter the shape memory capabilities but only the early recovery stage. Therefore, the memory of the system did not fade with relaxation time, but its elastic spring-back recovery increased.

The shape memory behavior under flexure was measured on specimens with an inherent I-shape, folded at $60{ }^{\circ} \mathrm{C}$ in a U-shaped configuration and cooled to $-20{ }^{\circ} \mathrm{C}$. Their recovery behavior was measured both as a function of temperature (TSR tests) and as a function of time (isothermal tests at $37^{\circ} \mathrm{C}$ ). The results are reported in Fig $9 \mathrm{a}$ and b, for the TSR and isothermal experiments.
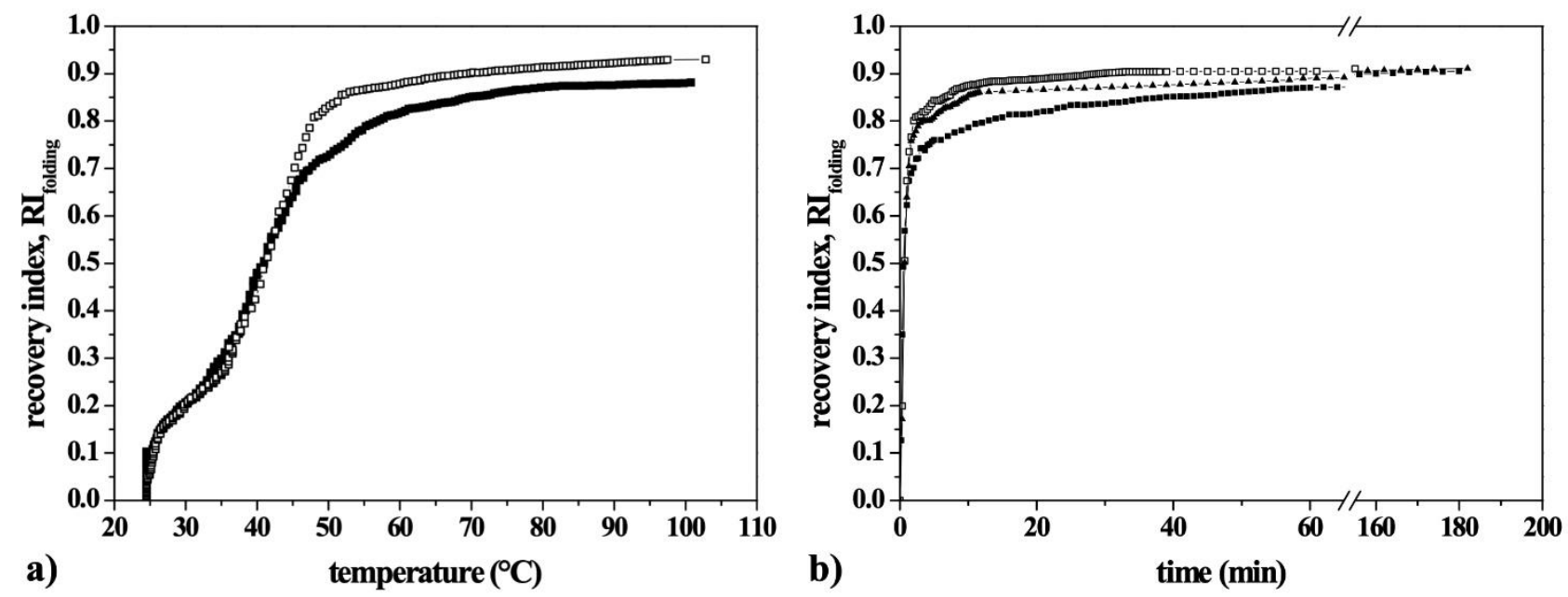

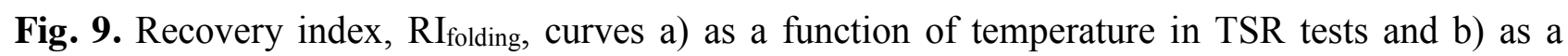
function of time in isothermal recovery tests at $37^{\circ} \mathrm{C}$, depicting their recovery from folded U-shape to the inherent I-shape as a function of temperature and time, respectively.

The results of the TSR tests were consistent with those obtained under tensile configuration, displaying a recovery process that is active already at room temperature and achieves significant speed at about $45{ }^{\circ} \mathrm{C}$, finally recovering around $90 \%$ of the applied angle. The maximum recovery was measured at $100{ }^{\circ} \mathrm{C}$, but the process may be considered practically fully achieved already at 50$55{ }^{\circ} \mathrm{C}$. Interestingly, isothermal recovery tests at $37^{\circ} \mathrm{C}$ clearly showed that such recovery degrees may be reached also at human body temperature, requiring only few minutes to reach $70 \%$ of the permanent shape, and a time span that ranges between 10 to 40 minutes for the process to be completed.

A test concerning the effect of the relaxation step was also carried out for this type of geometry, by maintaining the specimens in the constrained U-shape at room temperature for times varying between 1 to 50 days. The corresponding $\mathrm{RI}_{\text {folding }}$ curves are reported as a function of time in Fig. 10 as average 
recovery index for a same recovery time among three replicates. Error bars were not reported to provide readability, but they can be found in Table 1 for given instants.

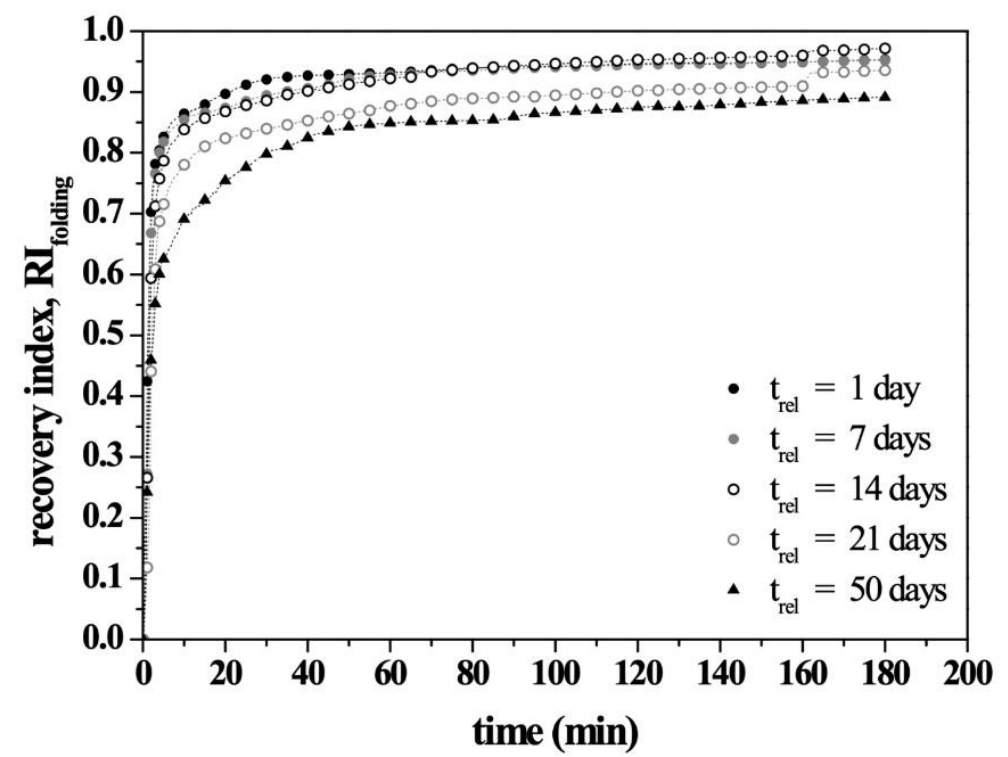

Fig. 10. Recovery index, $\mathrm{RI}_{\text {folding, }}$, curves for isothermal experiments carried out at $37^{\circ} \mathrm{C}$ on U-shaped folded specimen maintained in that shape at room temperature for various relaxation times $t_{\text {rel }}(1,7$, 14, 21, 50 days) before the recovery experiment.

\begin{tabular}{|c|c|c|c|c|}
\hline $\begin{array}{c}\text { Relaxation time, } \\
\mathrm{t}_{\text {rel }}(\mathrm{d})\end{array}$ & $\begin{array}{c}\mathrm{RI} \mathrm{I}_{\text {folding }} \\
\text { at } 1 \mathrm{~min}\end{array}$ & $\begin{array}{c}\mathrm{RI}_{\text {folding }} \\
\text { at } 10 \mathrm{~min}\end{array}$ & $\begin{array}{c}\mathrm{RI}_{\text {folding }} \\
\text { at } 20 \mathrm{~min}\end{array}$ & $\begin{array}{c}\mathrm{RI}_{\text {folding }} \\
\text { at } 180 \mathrm{~min}\end{array}$ \\
\hline 1 & $0.42 \pm 0.28$ & $0.86 \pm 0.05$ & $0.90 \pm 0.04$ & $0.95 \pm 0.02$ \\
\hline 7 & $0.27 \pm 0.14$ & $0.85 \pm 0.01$ & $0.87 \pm 0.02$ & $0.95 \pm 0.03$ \\
\hline 14 & $0.26 \pm 0.18$ & $0.84 \pm 0.08$ & $0.87 \pm 0.08$ & $0.97 \pm 0.04$ \\
\hline 21 & $0.12 \pm 0.12$ & $0.78 \pm 0.05$ & $0.82 \pm 0.04$ & $0.93 \pm 0.01$ \\
\hline 50 & $0.24 \pm 0.12$ & $0.69 \pm 0.10$ & $0.75 \pm 0.09$ & $0.89 \pm 0.03$ \\
\hline
\end{tabular}

Table 1. Recovery index $\mathrm{RI}_{\text {folding }}$ data, measured at various recovery times in isothermal experiments carried out at $37{ }^{\circ} \mathrm{C}$ on U-shaped folded specimens which were maintained in that shape at room temperature for various relaxation times $(1,7,14,21,50$ days $)$ before activating recovery.

The average curves of Fig. 10 clearly showed a similar shape memory response over time, with a significant recovery (at least about 70\%) in the first 10 minutes. It was then followed by a recovery 20 
of reduced rate, the latter being almost the same rate independent of the relaxation time, which led to a total recovery between 90 and $95 \%$ in the subsequent 3 hours. However, on the average, the specimens displayed lower recovery at any given instant as the relaxation time increased. In particular, this effect was evident for long relaxation times (21 and 50 days, respectively), whereas for relaxation up to 14 days the effect may be considered of minor importance.

In conclusion, the significant extent of recovery reached in the first 10 minutes, independent of the relaxation time, suggested that the presence of a relaxation period, potentially represented by the encapsulation of the DDS, did not cancel the shape memory performance of the DDS, even if it slightly affects final level of recovery.

Considering the data reported in Table 1, the difference in the recovery index for a given time turned out to be less striking in light of the measurement scattering, although a slight divergence was maintained for the average recovery index.

\subsection{Model validation}

The shape memory response was modelled on the basis of the thermo-viscoelastic approach described in Section 2.4, in which the dependence of the mechanical behavior on time and temperature was based on the dynamic moduli master curves and on the shift factors dependence on temperature. Accordingly, model parameters were all identified from the experimental curves presented in previous sections.

The Prony parameters, $\bar{g}_{i}^{P}$ and $\tau_{\mathrm{i}}(\mathrm{i}=1, \ldots, \mathrm{N})$, represent the $2 \mathrm{~N}$ unknows defining the spring-damper elements of the adopted constitutive model and have to be determined from experimental data. In the present case, they were simultaneously determined from the storage and loss modulus master curves reported in Fig. 3b and 3c, starting from the optimization procedure introduced by Kraus et al. (2017). Particularly, in order to reduce the number of unknowns, we adopted the same number $\mathrm{N}$ for the spring-damper elements and the examined frequency decays, since one Maxwell Element per measured frequency decade can be considered sufficient to map the relaxation behavior (Kraus, 2017). Then, we assumed the relaxation times $\tau_{\text {i }}$ equal to certain positive values per decades, in order to reduce the number of unknowns from $2 \mathrm{~N}$ to $\mathrm{N}$.

Accordingly, the problem was formulated as a least square optimization problem, where the target function was expressed as a function of the unknown $N$ parameters $\left(\bar{g}_{1}^{P}, \ldots, \bar{g}_{N}^{P}\right)$, as follows (Kraus 2017):

$f\left(\bar{g}_{1}^{P}, \ldots, \bar{g}_{N}^{P}\right)=\sum_{i=1}^{N}\left[\left(\log G^{\prime}\left(\omega_{i}\right)-\log G_{\text {exp }}^{\prime}\left(\omega_{i}\right)\right)^{2}+10\left(\log G^{\prime \prime}\left(\omega_{i}\right)-\log G_{\text {exp }}^{\prime \prime}\left(\omega_{i}\right)\right)^{2}\right]$ 
subjected to thermodynamic constraints, i.e. $0 \leq \bar{g}_{i}^{P}<1, \sum_{i=1}^{N} \bar{g}_{i}^{P} \leq 1$, and $G_{\infty}=G_{0}\left(1-\sum \bar{g}_{i}^{P}\right)$. In Eq. (11) $G_{\text {exp }}^{\prime}$ and $G_{\text {exp }}^{\prime \prime}$ represent, respectively, the storage and loss modulus obtained experimentally.

This problem was solved using a two-step procedure. In the first step, the problem was solved by a genetic algorithm; in the second step, the $\mathrm{N}$ parameters resulting from the first step were used as initial guess parameters in a global gradient based optimization tool in order to find the final fitting parameters.

The optimization problem was implemented in Matlab, by choosing N=33 Maxwell elements. Table 2 reports the obtained parameters as $\bar{g}_{i}^{P}$ and $\tau_{\mathrm{i}}$ couples.

\begin{tabular}{|c|c|}
\hline $\bar{g}_{i}^{P}$ & $\tau_{\mathrm{i}}(\mathrm{s})$ \\
\hline 0.00374141 & $1.00 \mathrm{E}-21$ \\
\hline 0.00375453 & $1.00 \mathrm{E}-20$ \\
\hline 0.00388872 & $1.00 \mathrm{E}-19$ \\
\hline 0.00576913 & $1.00 \mathrm{E}-18$ \\
\hline 0.126106 & $1.00 \mathrm{E}-17$ \\
\hline 0.0858064 & $1.00 \mathrm{E}-16$ \\
\hline 0.0663233 & $1.00 \mathrm{E}-15$ \\
\hline 0.0675624 & $1.00 \mathrm{E}-14$ \\
\hline 0.04612 & $1.00 \mathrm{E}-13$ \\
\hline 0.056199 & $1.00 \mathrm{E}-12$ \\
\hline 0.0528531 & $1.00 \mathrm{E}-11$ \\
\hline
\end{tabular}

\begin{tabular}{|c|c|}
\hline $\bar{g}_{i}^{P}$ & $\tau_{\mathrm{i}}(\mathrm{s})$ \\
\hline 0.0607589 & $1.00 \mathrm{E}-10$ \\
\hline 0.0802685 & $1.00 \mathrm{E}-09$ \\
\hline 0.0742552 & $1.00 \mathrm{E}-08$ \\
\hline 0.0940951 & $1.00 \mathrm{E}-07$ \\
\hline 0.061216 & $1.00 \mathrm{E}-06$ \\
\hline 0.0538247 & $1.00 \mathrm{E}-05$ \\
\hline 0.0237761 & 0.0001 \\
\hline 0.0148667 & 0.001 \\
\hline 0.00610823 & 0.01 \\
\hline 0.0032505 & 0.1 \\
\hline 0.00197859 & 1 \\
\hline
\end{tabular}

\begin{tabular}{|c|c|}
\hline $\bar{g}_{i}^{P}$ & $\tau_{\mathrm{i}}(\mathrm{s})$ \\
\hline 0.00102984 & 10 \\
\hline 0.000989874 & 100 \\
\hline 0.00066613 & 1000 \\
\hline 0.000693835 & 10000 \\
\hline 0.000649501 & 100000 \\
\hline 0.00053126 & $1.00 \mathrm{E}+06$ \\
\hline 0.000536651 & $1.00 \mathrm{E}+07$ \\
\hline 0.000302641 & $1.00 \mathrm{E}+08$ \\
\hline 0.000310251 & $1.00 \mathrm{E}+09$ \\
\hline $6.80 \mathrm{E}-05$ & $1.00 \mathrm{E}+10$ \\
\hline 0.000322855 & $1.00 \mathrm{E}+11$ \\
\hline
\end{tabular}

Table 2. Prony parameters of the generalized Maxwell model: normalized moduli, $\bar{g}_{i}^{P}$ and relaxation times, $\tau_{\mathrm{i}}$, evaluated at $\mathrm{T}_{0}=60^{\circ} \mathrm{C}$.

These parameters allowed to obtain a good fit of the experimental behavior, as shown in Fig. 11a and $11 \mathrm{~b}$, in which experimental and calibrated curves are shown for the storage and loss modulus, respectively. 

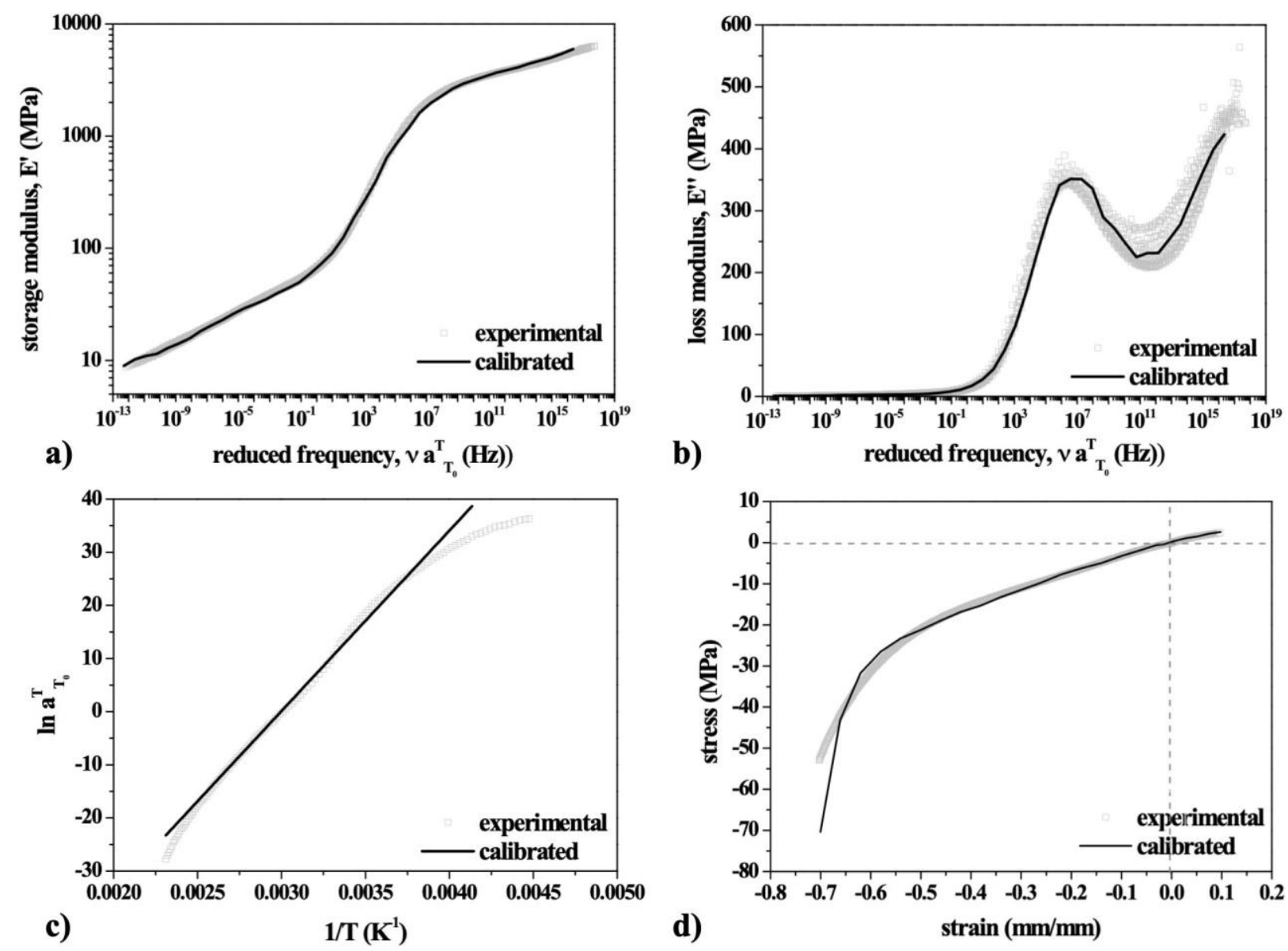

Fig. 11. Experimental curves (grey dots) versus fitted (black solid line) for: a) the storage modulus; b) the loss modulus; c) Arrhenius approximation of the calculated horizontal shift factors and d) experimental stress-strain curve (both under tension and compression) versus fitted curve at $60{ }^{\circ} \mathrm{C}$.

The shift factors employed for the master curve construction, allowing to describe the timetemperature dependence, were interpolated by the Arrhenius equation (Eq. 8), whose parameters were identified based on the experimental shift factor versus $1 / \mathrm{T}$ correlation represented in Fig. $3 \mathrm{~d}$. The Arrhenius equation was chosen as easier to implement in the computational framework and still providing a good approximation over a large set of data. The parameter $\mathrm{T}_{0}$ was assumed equal to the reference temperature, i.e. $\mathrm{T}_{0}=60{ }^{\circ} \mathrm{C}$, while the parameter $\mathrm{E}_{0}$ was fitted on a region of temperature between $-20{ }^{\circ} \mathrm{C}\left(1 / \mathrm{T}=0.0039 \mathrm{~K}^{-1}\right)$ and $115^{\circ} \mathrm{C}\left(1 / \mathrm{T}=0.0026 \mathrm{~K}^{-1}\right)$, i.e. the region where the curve in Fig. $3 \mathrm{~d}$ exhibits a fairly regular linear correlation. The interval was chosen since it offered a good coverage of the temperatures involved in the shape memory cycle. The parameter $\mathrm{E}_{0}$ for the Arrhenius equation was taken equal to $282.38 \mathrm{~kJ} /$ mole. The comparison between the calibrated and experimental curves is reported in Fig. 11c. 
The Yeoh model parameters, as introduced in Eq. (9), were identified on the stress versus strain curves of Fig. 5, both for the tensile and compression behavior measured at $60{ }^{\circ} \mathrm{C}$, obtaining the parameters $\mathrm{C}_{10}=4977901.74 \mathrm{MPa}, \mathrm{C}_{20}=-1063924.80 \mathrm{MPa}$, and $\mathrm{C}_{30}=148187.61 \mathrm{MPa}$. The experimental and modelled curves are shown in Fig. 11d.

The model was then validated on the experimental results regarding the flexural configuration (i.e. bending the specimen between a straight I-shaped configuration to a folded U-shaped one as described in Section 3.3). Accordingly, the specimen geometry was meshed by using eight-node linear isoparametric hexahedral elements, reduced integration with hourglass control, hybrid with constant pressure. A quasi-static analysis was performed by imposing appropriate boundary conditions and temperature history, as detailed in the following. Temperature was assumed uniform in the bar.

First, the TSR test was simulated. The geometry, the coordinate system, and the applied boundary conditions are provided in Fig. $12 \mathrm{~b}$. A pressure, $p=3000 \mathrm{MPa}$, was imposed on the half bar at $60{ }^{\circ} \mathrm{C}$ to bend the bar from a straight I-shaped configuration to a folded U-shaped one. The pressure caused the bending of the bar of an angle $\alpha_{\text {prog. }}$ The deformed U-shaped bar was kept in position during cooling up to $-20{ }^{\circ} \mathrm{C}$ to simulate the programming step. Afterwards, the constraints were removed from the bar, which was subjected to a heating ramp up to $100^{\circ} \mathrm{C}$ to induce shape recovery.

Experimental and numerical results are compared in Fig. 12a, where $\mathrm{RI}_{\text {folding }}$ is represented as a function of temperature. The permanent shape, the programmed shape, and the recovered shapes at $50{ }^{\circ} \mathrm{C}$ and $70{ }^{\circ} \mathrm{C}$ are reported in Fig. $12 \mathrm{~b}$. 


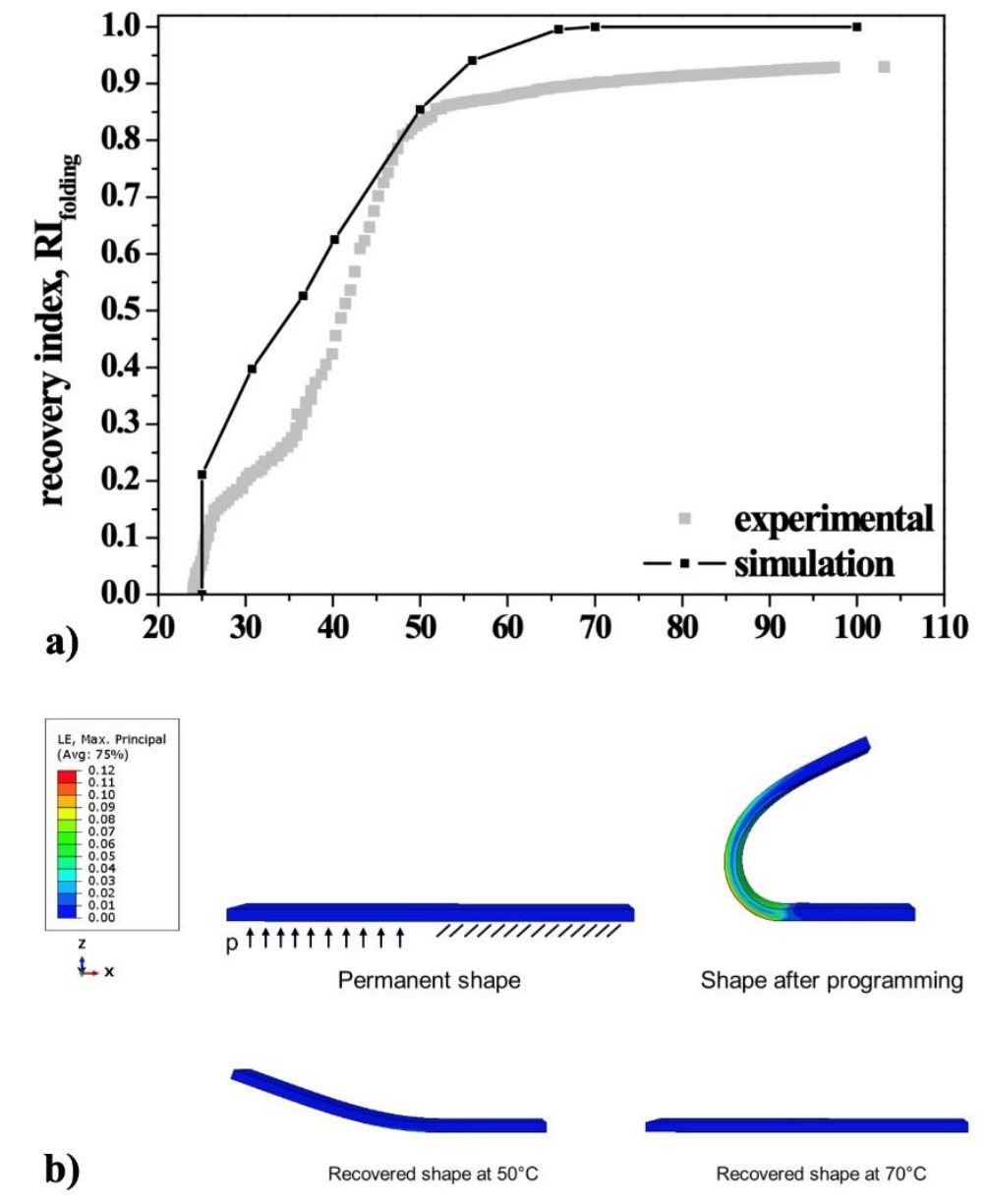

Fig. 12. a) Comparison between experimental (grey open squares) and numerical (black full

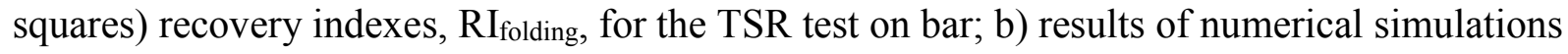
showing the contour plot of the maximum principal logarithmic strain.

The predicted curve had a trend similar to the experimental one, suggesting that recovery takes place across similar region and with a similar dependence on temperature. However, the model slightly overpredicted the experimental response, so that at most temperatures the predicted recovery index turned out to be higher than that measured experimentally. This may be partly due to a thermal lag experienced by the specimens during the heating ramp, which is not taken into account by the model. Furthermore, the model reasonably did not consider the presence of an irreversible strain, predicting complete recovery, as it is shown in Fig. 12b with the permanent straight I-shaped configuration fully recovered at $70{ }^{\circ} \mathrm{C}$.

Then, the isothermal test was simulated on a rod-shapes sample. The coordinate system and the applied boundary conditions are the same provided in Fig. 12b. Similarly to the previous simulation, a pressure, $p=3000 \mathrm{MPa}$, was imposed on half rod at $60^{\circ} \mathrm{C}$. The deformed U-shaped rod was then kept in position during cooling up to $-20^{\circ} \mathrm{C}$. Finally, the constraints were removed from the deformed 25 
rod, which was brought up to $37^{\circ} \mathrm{C}$. The rod was kept at $37^{\circ} \mathrm{C}$ for $500 \mathrm{~min}$ to induce shape recovery. In Fig. 13, numerical results based on the aforementioned parameters (black open squares) were compared to experimental data (grey open squares) in terms of the recovery index $\mathrm{RI}_{\text {folding. }}$ The curves qualitatively showed a similar response, with a faster increase in the first 20 minutes followed by a relatively slower recovery. However, in this case, the model strongly underpredicted the recovery index measured at a certain instant. Indeed, a slower recovery process was predicted, and the poor agreement with the measured data is supposed to be related to a non-adequate description of the timetemperature correlation. As shown in Fig.13, the permanent straight I-shaped configuration was not fully recovered after $160 \mathrm{~min}$.

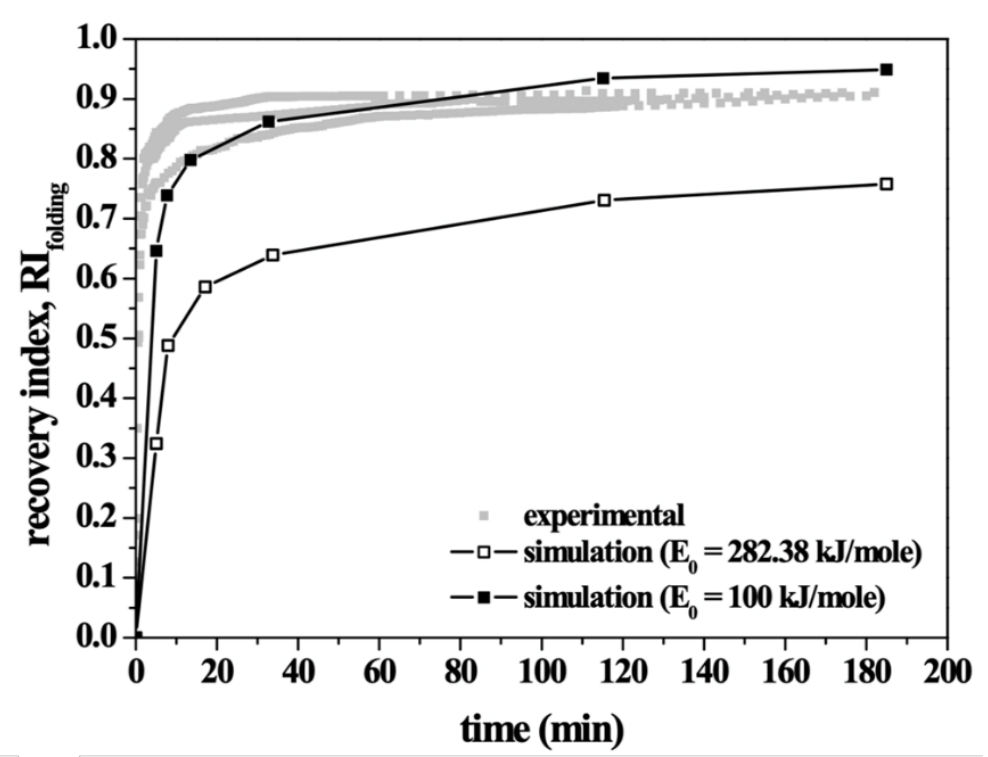

Fig. 13. Comparison between experimental (grey open squares) and numerical (black open squares: $\mathrm{E}_{0}=282.38 \mathrm{~kJ} /$ mole; black full squares: $\mathrm{E}_{0}=100 \mathrm{~kJ} / \mathrm{mole}$ ) recovery indexes, $\mathrm{RI}_{\text {folding, for isothermal }}$ tests at $37^{\circ} \mathrm{C}$ on rods.

Such a deviation between the simulation curve and the experimental recovery curve was not fully unexpected, since under isothermal conditions even slight differences between the material behavior and the one predicted by extrapolated parameters may determine important differences on the recovery time scales. Indeed, this is particularly likely to occur when the recovery process is happening in proximity of the glass transition.

For this reason, in order to improve the model prediction capability under isothermal conditions, without abandoning the Arrhenius equation that may be easily implemented in Abaqus, the value of the parameter $\mathrm{E}_{0}$ was determined following a trial and error approach, until a good matching between the isothermal recovery curves was found. The numerical results under this latter modification (black full squares), obtained with an $\mathrm{E}_{0}$ value equal to $100 \mathrm{~kJ} / \mathrm{mol}$, clearly demonstrated a better agreement. 
Two considerations have to be remarked. First, for this specific material, a full description of the shape memory response on the basis of sole DMA results is not possible, probably due to the complex chains motion occurring in a semicrystalline material, as well as to the fact that isothermal experiments and simulations were performed in condition strongly dominated by the viscoelastic behavior, since temperature was very close the material $\mathrm{T}_{\mathrm{g}}$. The improved response obtained following a change in $\mathrm{E}_{0}$, which may be derived from the isothermal curves, suggested, as a potential strategy, to calibrate both the Prony series parameters of the model based on the DMA results, and the $\mathrm{E}_{0}$ value directly on an isothermal shape recovery curve. In addition, the new $\mathrm{E}_{0}$ value for the Arrhenius-like equation is lower than that obtained from the shift factors employed for the master curve construction. This may also be reasonable, as the relaxation chain motion taking place during DMA regards small strain deformation and, in this case, $\mathrm{E}_{0}$ represented the activation energy for relaxation motions. Conversely, the shape recovery phenomenon generally involves larger strains, proper of a non-linear viscoelastic response, whose recovery may be based on motions requiring lower activation energy, due to the stored internal energy and the larger free volume.

\subsection{Shape memory performance of extruded prototypes and modelling the response}

The shape recovery of S-shaped samples from the temporary planar paper-clip shape suitable for capsule administration was evaluated upon immersion of samples in aqueous medium kept at $37^{\circ} \mathrm{C}$ and by monitoring three angles (i.e. $\alpha_{\mathrm{xy}}, \alpha_{\mathrm{yz}}$ and $\alpha_{\mathrm{xz}}$ ) (Fig. 2). This way, it was possible to calculate three corresponding recovery indexes, whose evolution over time is reported in Fig. 14. The specimens showed a very efficient recovery response. Interestingly after the first $30 \mathrm{~s}$, all the angles increased enough to make the system reaching a size compatible with gastric retention, as detailed by Melocchi et al. (2019b). Particularly, $\alpha_{x y}$ increases up to $52^{\circ} \pm 4^{\circ}$, well above the $43^{\circ}$ required for retention. Similarly, $\alpha_{\mathrm{yz}}$ opened up to $43^{\circ} \pm 22^{\circ}$ (angle required: $32^{\circ}$ ), while $\alpha_{\mathrm{xz}}$ reached $59^{\circ} \pm 4^{\circ}$ (angle required: $33^{\circ}$ ). In this respect, the prototypes demonstrated the ability to recover the original shape, and although the tests lasted up to $20 \mathrm{~min}, 3-4$ minutes were enough for the specimens to achieve a steady state in their shape recovery. Actually, some of them seemed to over-recover the applied strain, being characterized by a steady state recovery index close to $110 \%-120 \%$. This may be associated with the presence of frozen-in stresses in the extruded bars or with inadequate fixing of the S shape. 

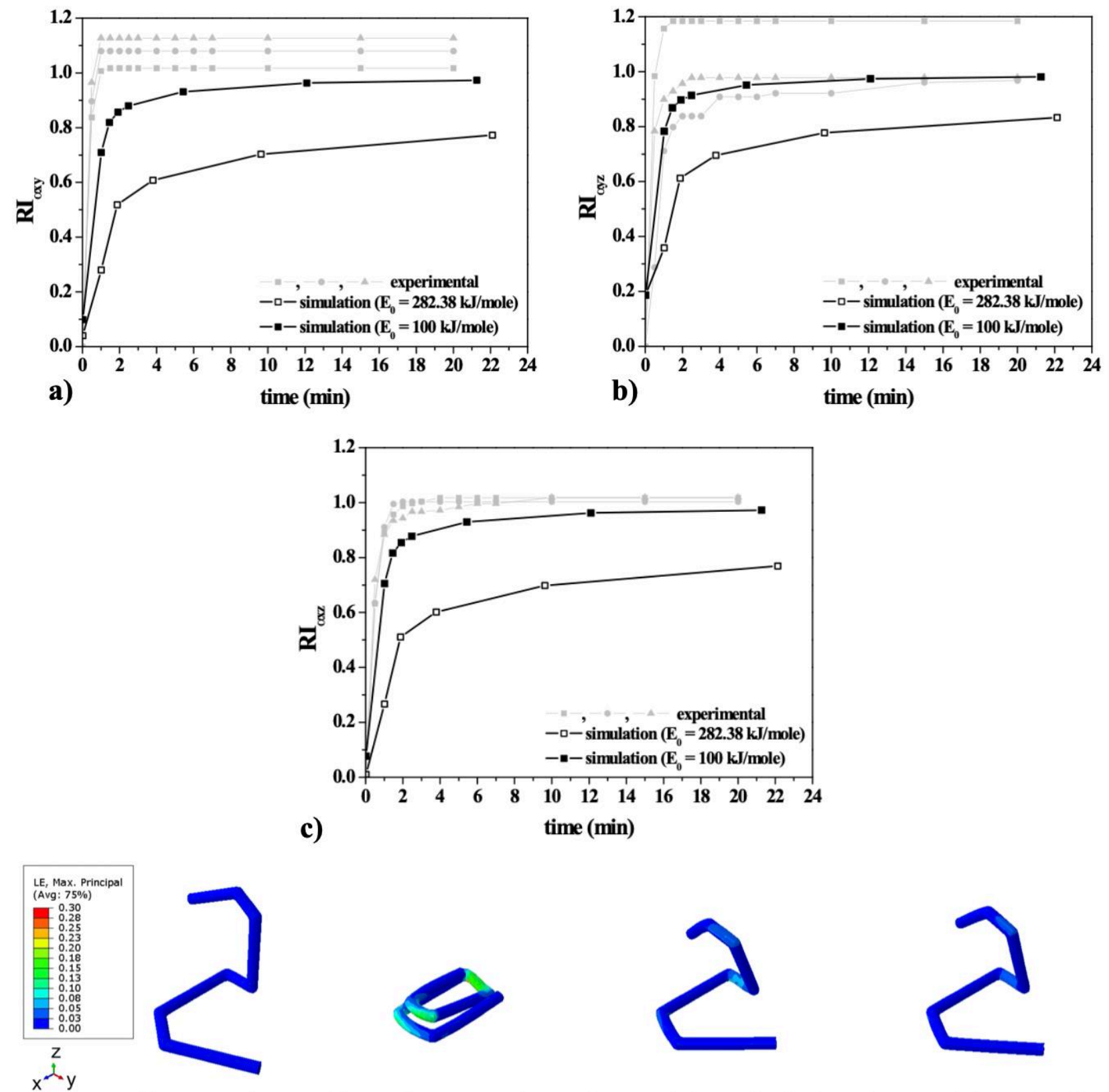

d) Permanent shape Shape after programming Recovered shape after $7 \mathrm{~min} \quad$ Recovered shape after $21 \mathrm{~min}$
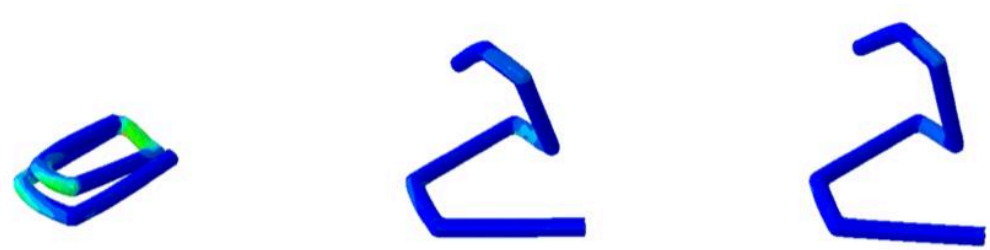

Fig. 14. Comparison between experimental (grey full squares) and numerical (black open squares: $E_{0}$ $=282.38 \mathrm{~kJ} / \mathrm{mole}$; black full squares: $\mathrm{E}_{0}=100 \mathrm{~kJ} / \mathrm{mole}$ ) recovery indexes, $\mathrm{RI}$, for isothermal tests at $37^{\circ} \mathrm{C}$ on prototypes. Recovery Index curves: a) $\mathrm{RI}_{\alpha, x y}$, b) $\mathrm{RI}_{\alpha, y z}$, c) $\mathrm{RI}_{\alpha, x z}$. d) Results of numerical simulations with $\mathrm{E}_{0}=282.38 \mathrm{~kJ} /$ mole, showing the contour plot of the maximum principal logarithmic strain.

The model was checked also by performing a numerical simulation on S-shaped prototypes deformed to take on a paper-clip shape. Accordingly, the clip geometry was meshed by using four-node linear tetrahedron, hybrid with linear pressure. A quasi-static analysis was performed by imposing appropriate boundary conditions and temperature history. The temperature field was assumed to be 
uniform in the clip. The geometry and the coordinate system are provided in Fig. 14d. A pressure was imposed to deform the prototype in a paper-clip configuration. To avoid penetration during the deformation, a surface-to-surface contact was activated on the model. In particular, a 0.03 friction contact was adopted, enforced by linear penalty method.

The deformed prototype was kept in position during cooling, until a temperature of $-20{ }^{\circ} \mathrm{C}$ was reached. At that point, constraints were removed from the deformed clip, the clip was heated up to $37{ }^{\circ} \mathrm{C}$, maintaining it at this temperature for $90 \mathrm{~min}$ to observe shape recovery. The results of the numerical simulation and particularly, the shapes attained after $7 \mathrm{~min}$ and $21 \mathrm{~min}$ of recovery are presented in Fig. 14.

As evident from Fig. 14, the original shape was not fully recovered after $21 \mathrm{~min}$, suggesting also in this case that the predicted trend is slower than the real response, and the need for resorting to a change in $E_{0}$ to improve the model prediction ability. In this respect, a value of $100 \mathrm{~kJ} / \mathrm{mole}$ was applied, as derived from the good matching between experiments and simulation in the case of the folded rods. The adoption of this value, derived from relatively simple isothermal recovery experiments, allowed to obtain a significantly improved agreement between experiments and simulation.

\section{Conclusions}

In this work, the possibility of describing by computer-aided simulation modelling the shape-shifting response of DDSs based on pharmaceutical-grade shape memory polymers was investigated. In this respect, a specific prototype made of plasticized PVA was developed. It consisted in a three dimensional S-shaped item with a temporary planar shape (i.e. paper-clip shape). The recovery process under isothermal conditions exhibited a significantly high rate for temperature close to, or above, the human body temperature. In particular, at $37{ }^{\circ} \mathrm{C}$ about $70 \%$ of the original shape was recovered in only few minutes. The simulation activity was pursued within a finite element analysis framework, by using the software Abaqus. A 3D generalized Maxwell thermo-viscoelastic model, whose parameters were fitted from the data obtained through $i$ ) DMTA experiments (at small strains, in the linear viscoelastic region) and $i$ ) tensile and compression tests in quasi-static conditions above the material $\mathrm{T}_{\mathrm{g}}$, was integrated into Abaqus. An Arrhenius-type dependence on temperature, driven by the value of a single parameter that is the activation energy $\mathrm{E}_{0}$, was considered for the timetemperature shift factors.

The modeling approach here adopted turned out to be effective in simulating the shape memory behavior of the DDS prototype, when using an appropriate value of $\mathrm{E}_{0}$. In fact, due to the high complexity of the viscoelastic response of the material at the recovery temperature, which is quite 
close to the material $\mathrm{T}_{\mathrm{g}}$, the use of an $\mathrm{E}_{0}$ value determined in the linear viscoelastic regime may be inadequate. The strategy here proposed for the selection of the proper $\mathrm{E}_{0}$ for the simulation consisted in considering the latter as an adjustable parameter, whose value could be determined from shape recovery isothermal tests carried out on a sample based on the material of interest with a very simple shape. By pursuing this strategy, the modeling approach proposed in this paper could be easily exploited and used in support of the design of DDSs composed of shape memory polymers.

\section{Conflicts of interest}

The authors declare that they have no known competing financial interests or personal relationships that could have appeared to influence the work reported in this paper.

\section{Acknowledgments}

The authors kindly acknowledge Mrs. Giulia Tameni for contributing to the shape memory characterization. This work was partially supported by the Italian Minister of University and Research through the project "A BRIDGE TO THE FUTURE: Computational methods, innovative applications, experimental validations of new materials and technologies" (No. 2017L7X3CS) within the PRIN 2017 program and by the INSTM Consortium through the project "Nuovi materiali e approcci computazionali per stampa 4D”.

\section{References}

Altreuter, D.H., Kirtane, A.R., Grant, T., Kruger, C., Traverso, G., Bellinger, A.M., 2018. Changing the pill: developments towards the promise of an ultra-long-acting gastroretentive dosage form. Expert Opin. Drug. Del. 15 (12), 1189-1198.

Babaee, S., Pajovic, S., Kirtane, A.R., Shi, J., Caffarel-Salvador, E., Hess, K., Collins, J.E., Tamang, S., Wahane, A.V., Hayward, A.M., Mazdiyasni, H., Langer, R., Traverso, G., 2019. Temperatureresponsive biometamaterials for gastrointestinal applications. Sci. Transl. Med. 11 (488), eaau8581. 
Bai, Y., Zhang, J., Chen, X., 2018. A thermal-, water-, and near-infrared light-induced shape memory composite based on polyvinyl alcohol and polyaniline fibers. ACS Appl. Mater. Inter. 10 (16), 1401714025.

Baker, R.M., Tseng, L.-F., Iannolo, M.T., Oest, M.E., Henderson, J.H., 2016. Self-deploying shape memory polymer scaffolds for grafting and stabilizing complex bone defects: A mouse femoral segmental defect study. Biomaterials 76, 388-398.

Balk, M., Behl, M., Wischke, C., Zotzmann, J., Lendlein, A., 2016. Recent advances in degradable lactide-based shape-memory polymers. Adv. Drug Deliver. Rev 107, 136-152.

Bearinger, J.P., Maitland, D.J., Schumann, D.L., Wilson, T.S., 2014. System for closure of a physical anomaly. Patent No. US 8,882,786 B2.

Behl, M., Lendlein, A., 2007. Shape-memory polymers. Mater. Today 10 (4), 20-28.

Bellinger, A.M., Jafari, M., Grant, T.M., Zhang, S., Slater, H.C., Wenger, E.A., Mo, S., Lee, Y.A.L., Mazdiyasni, H., Korgan, L., Barman, R., Cleveland, C., Booth, L., Bensel, T., Minahan, D., Hurowitz, H.M., Tai, T., Daily, J., Nikolic, B., Wood, L., Eckhoff, P.A., Langer, R., Traverso, G., 2016. Oral, ultra-long-lasting drug delivery: Application toward malaria elimination goals. Sci. Transl. Med. 8 (365), 365ra157.

Boatti, E., Scalet, G., Auricchio, F., 2016. A three-dimensional finite-strain phenomenological model for shape-memory polymers: Formulation, numerical simulations, and comparison with experimental data. Int. J. Plasticity 83, 153-177.

Boyle, A.J., Landsman, T.L., Wierzbicki, M.A., Nash, L.D., Hwang, W., Miller, M.W., Tuzun, E., Hasan, S.M., Maitland, D.J., 2016. In vitro and in vivo evaluation of a shape memory polymer foam over -wire embolization device delivered in saccular aneurysm models. J. Biomed. Mater. Res. B 104 (7), 1407-1415.

Chen, Y.-C., Lagoudas, D.C., 2008. A constitutive theory for shape memory polymers. Part I. large deformations. J. Mech. Phys. Solids 56 (5), 1752-1765.

Chen, H., Li, Y., Tao, G., Wang, L., Zhou, S., 2016. Thermo- and water-induced shape memory poly(vinyl alcohol) supramolecular networks crosslinked by self-complementary quadruple hydrogen bonding. Polym. Chem.-UK 7 (43), 6637-6644.

Chen, T., Bilal, O.R., Shea, K., Daraio, C., 2018. Harnessing bistability for directional propulsion of soft, untethered robots. P. Natl. Acad. Sci. USA 115 (22), 5698-5702. 
DeMerlis, C.C., Schoneker, D.R., 2003. Review of the oral toxicity of polyvinyl alcohol (PVA). Food Chem Toxicol., 41 (3), 319-326

Diani, J., Liu, Y., Gall, K., 2006. Finite strain 3D thermoviscoelastic constitutive model for shape memory polymers. Polym. Eng. Sci. 46 (4), 484-492.

Diani, J., Gilormini, P., Frédy, C. and Rousseau, I., 2012. Predicting thermal shape memory of crosslinked polymer networks from linear viscoelasticity. Int. J. Solids Struct. 49 (5), 793-799.

Du, H., Zhang, J., 2010a. Shape memory polymer based on chemically cross-linked poly(vinyl alcohol) containing a small number of water molecules. Colloid Polym. Sci., 288 (1), 15-24.

Du, H., Zhang, J., 2010b. Solvent induced shape recovery of shape memory polymer based on chemically cross-linked poly(vinyl alcohol). Soft Matter 6 (14), 3370-3376.

Du, H., Yu, Y., Jiang, G., Zhang, J. and Bao, J., 2011. Microwave-induced shape-memory effect of chemically crosslinked moist poly(vinyl alcohol) networks. Macromol. Chem. Phys. 212 (14), 14601468.

Du, H., Song, Z., Wang, J., Liang, Z., Shen, Y., You, F., 2015. Microwave-induced shape-memory effect of silicon carbide/poly(vinyl alcohol) composite. Sensor. Actuat. A-Phys. 228, 1-8.

Du, F.-P., Ye, E.-Z., Yang, W., Shen, T.-H., Tang, C.-Y., Xie, X.-L., Zhou, X.-P., Law, W.-C., 2015. Electroactive shape memory polymer based on optimized multi-walled carbon nanotubes/polyvinyl alcohol nanocomposites. Compos. Part B-Eng. 68, 170-175.

Fang, Z., Kuang, Y., Zhou, P., Ming, S., Zhu, P., Liu, Y., Ning, H., Chen, G., 2017. Programmable shape recovery process of water-responsive shape-memory poly(vinyl alcohol) by wettability contrast strategy. ACS Appl. Mater. Inter. 9 (6), 5495-5502.

Firth J., Gaisford S., Basit A.W., 2018. A New Dimension: 4D Printing Opportunities in Pharmaceutics. In: Basit A., Gaisford S. (eds) 3D Printing of Pharmaceuticals. AAPS Advances in the Pharmaceutical Sciences Series, vol 31. Springer, Cham

Gall, K., Yakacki, C.M., Liu, Y., Shandas, R., Willett, N., Anseth, K.S., 2005. Thermomechanics of the shape memory effect in polymers for biomedical applications. J. Biomed. Mater. Res. A 73 (3), 339-348.

Gilormini P., Diani J., 2012. On modeling shape memory polymers as elastic two phase composite materials. CR Mécanique 340 (4-5), 338-348. 
Gong, T., Zhao, K., Yang, G., Li, J., Chen, H., Chen, Y., Zhou, S., 2014. The control of mesenchymal stem cell differentiation using dynamically tunable surface microgrooves. Adv. Healthc. Mater. 3 (10), 1608-1619.

Hong, S.J., Yu, W.R., Youk, J.H., Cho, Y.R., 2007. Polyurethane smart fiber with shape memory function: experimental characterization and constitutive modeling. Fiber. Polym. 8 (4), 377-385.

Kirillova, A., Ionov, L., 2019. Shape-changing polymers for biomedical applications. J. Mater. Chem. B 7 (10), 1597-1624.

Kirtane, A.R., Abouzid, O., Minahan, D., Bensel, T., Hill, A.L., Selinger, C., Bershteyn, A., Craig, M., Mo, S.S., Mazdiyasni, H., Cleveland, C., Rogner, J., Lee, Y.-A.L., Booth, L., Javid, F., Wu, S.J., Grant, T., Bellinger, A.M., Nikolic, B, Hayward, A., Wood, L., Eckhoff, P.A., Nowark, M.A., Langer, R., Traverso, G., 2018. Development of an oral once-weekly drug delivery system for HIV antiretroviral therapy. Nat. Commun. 9 (1), 2294.

Kraus, M.A., Schuster, M., Kuntsche, J., Siebert, G., Schneider, J., 2017. Parameter identification methods for visco- and hyperelastic material models. Glass Struct. Eng. 2, 147-167.

Kunkel, R., Laurence, D., Wang, J., Robinson, D., Scherrer, J., Wu, Y., Bohnstedt, B., Chien, A., Liu, Y., Lee, C.-H., 2018. Synthesis and characterization of bio-compatible shape memory polymers with potential applications to endovascular embolization of intracranial aneursyms. J. Mech. Behav. Biomed. 88, 422-430.

Landsman, T.L., Bush, R.L., Glowczwski, A., Horn, J., Jessen, S.L., Ungchusri, E., Diguette, K., Smith, H.R., Hasan, S.M., Nash, D., Clubb, F.J., Jr., Maitland, D.J., 2016. Design and verification of a shape memory polymer peripheral occlusion device. J. Mech. Behav. Biomed. 63, 195-206.

Lendlein, A., Langer, R., 2002. Biodegradable, elastic shape-memory polymers for potential biomedical applications. Science 296 (5573), 1673-1676.

Lendlein, A., Langer, R., 2012. Biodegradable shape memory polymeric sutures. Patent No. US $8,303,625 \mathrm{~B} 2$.

Lin, J.R., Chen, L.W., 1999. Shape-memorized crosslinked ester-type polyurethane and its mechanical viscoelastic model. J. Appl. Polym. Sci. 73 (7), 1305-1319.

Liu, Y., Gall, K., Dunn, M.L., Greenberg, A.R., Diani, J., 2006. Thermomechanics of shape memory polymers: uniaxial experiments and constitutive modeling. Int. J. Plasticity 22 (2), 279-313. 
Maroni A., Melocchi A., Zema, L., Foppoli A., Gazzaniga A., 2019. Retentive drug delivery systems based on shape memory materials, J. Appl. Polym. Sci. 137 (25), 48798.

Melocchi, A, Inverardi, N., Uboldi, M., Baldi, F., Maroni, A., Pandini, S., Briatico-Vangosa, F., Zema, L., Gazzaniga, A., 2019a. Retentive device for intravesical drug delivery based on waterinduced shape memory response of poly(vinyl alcohol): design concept and 4D printing feasibility. Int. J. Pharm. 559, 299-311.

Melocchi, A., Uboldi, M., Inverardi, N., Briatico-Vangosa, F., Baldi, F., Pandini, S., Scalet, G., Auricchio, F., Cerea, M., Foppoli, A., Maroni, A., Zema, L., Gazzaniga, A., 2019b. Expandable drug delivery system for gastric retention based on shape memory polymers: Development via 4D printing and extrusion. Int. J. Pharm. 571, 118700.

Morshedian, J., Khonakdar, H.A., Rasouli, S., 2005. Modeling of shape memory induction and recovery in heat-shrinkable polymers. Macromol. Theory Simul. 14 (7), 428-434.

Muppalaneni, S., Omidian, H., 2013. Polyvinyl Alcohol in Medicine and Pharmacy: A Perspective. J Develop Drugs, 2 (3), 1000112.

Nguyen, T.D., Qi, H.J., Castro, F., Long, K.N., 2008. A thermoviscoelastic model for amorphous shape memory polymers: incorporating structural and stress relaxation. J. Mech. Phys. Solids 56 (9), 2792-2814.

Pandey, A., Singh, G., Singh, S., Jha, K., Prakash, C., 2020. 3D printed biodegradable functional temperature-stimuli shape memory polymer for customized scaffoldings J. Mech. Behav. Biomed. $108,103781$.

Paonessa, S., Barbani, N., Rocchietti, E.C., Giachino, C., Cristallini, C., 2017. Design and development of a hybrid bioartificial water-induced shape memory polymeric material as an integral component for the anastomosis of human hollow organs. Mater. Sci. Eng. C-Mater. 75, 1427-1434.

Peppas, N.A., Merrill, E.W., 1976. Differential scanning calorimetry of crystallized PVA hydrogels. J. Appl. Polym. Sci. 20 (6), 1457-1465.

Qi, X., Yao, X., Deng, S., Zhou, T., Fu, Q., 2014. Water-induced shape memory effect of graphene oxide reinforced polyvinyl alcohol nanocomposites. J. Mater. Chem. A 2 (7), 2240-2249.

Reese, S., Böl, M., Christ, D., 2010. Finite element-based multi-phase modeling of shape memory polymer stents. Comput. Methods Appl. Mech. Eng. 199 (21-22), 1276-1286. 
Salessiotis, N., 1972. Measurement of the diameter of the pylorus in man: Part I. Experimental project for clinical application. Am. J. Surg. 124 (3), 331-333.

Simo, J.C., 1987. On a fully three-dimensional finite strain viscoelastic damage model: formulation and computational aspects. Comput. Methods Appl. Mech. Eng. 60 (2), 153-173.

Small IV, W., Wilson, T.S., Benett, W.J., Loge, J.M., Maitland, D.J., 2005. Laser-activated shape memory polymer intravascular thrombectomy device. Opt. Express 13 (20), 8204-8213.

Srivastava, V., Chester, S.A., Anand, L., 2010. Thermally actuated shape-memory polymers: experiments theory, and numerical simulations. J. Mech. Phys. Solids 58 (8), 1100-1124.

Tobushi, H., Hashimoto, T., Hayashi, S., Yamada, E., 1997. Thermomechanical constitutive modeling in shape memory polymer of polyurethane series. J. Intel. Mater. Syst. Str. 8 (8), 711-718.

Tseng, L.-F., Mather, P.T., Henderson, J.H., 2013. Shape-memory-actuated change in scaffold fiber alignment directs stem cell morphology. Acta Biomater. 9 (11), 8790-8801.

Wang, Z.D., Li, D.F., Xiong, Z.Y., Chang, R.N., 2009. Modeling thermomechanical behaviors of shape memory polymer. J. Appl. Polym. Sci. 113 (1), 651-656.

Wang, L., Yang, X., Chen, H., Yang, G., Gong, T., Li, W., Zhou, S., 2013. Multi-stimuli sensitive shape memory poly(vinyl alcohol)-graft-polyurethane. Polym. Chem.-UK 4 (16), 4461-4468.

Wang, J., Quach, A., Brasch, M.E., Turner, C.E., Henderson, J.H., 2017. On-command on/off switching of progenitor cell and cancer cell polarized motility and aligned morphology via a cytocompatible shape memory polymer scaffold. Biomaterials 140, 150-161.

Wischke, C., Neffe, A.T., Steuer, S., Lendlein, A., 2009. Evaluation of a degradable shape-memory polymer network as matrix for controlled drug release. J. Control. Release 138 (15), 243-250.

Wischke, C., Lendlein, A., 2010. Shape-memory polymers as drug carriers - a multifunctional system. Pharm. Res. 27 (4), 527-529.

Xiao, Y., Zhou, S., Wang, L., Zheng, X., Gong, T., 2010. Crosslinked poly(Ecaprolactone)/poly(sebacic anhydride) composites combining biodegradation, controlled drug release and shape memory effect. Compos. Part B-Eng. 41 (7), 537-542.

Yakacki, C.M., Shandas, R., Lanning, C., Rech, B., Eckstein, A., Gall, K., 2007. Unconstrained recovery characterization of shape-memory polymer networks for cardiovascular applications. Biomaterials 28 (14), 2255-2263. 
Yarali, E., Taheri, A., Baghani, M., 2020. A comprehensive review on thermomechanical constitutive models for shape memory polymers. J. Intel. Mat. Syst. Str. 31 (10), 1243-1283.

Yeoh, O.H., 1993. Some forms of the strain energy function for rubber. Rubber Chem. Technol. 66 (5), 745-771.

Zhang, S., Bellinger, A.M., Glettig, D.L., Barman, R., Lee, Y.-A.L., Zhu, J., Cleveland, C., Montgomery, V.A., Gu, L., Nash, L.D., Maitland, D.J., Langer, R., Traverso, G., 2015. A pHresponsive supramolecular polymer gel as an enteric elastomer for use in gastric devices Nat. Mater. $14,1065-1071$.

https://www.gohsenol.com/doc_e/spcl/spcl_01/spcl_08.shtml Last access: April 2021

https://www.m-

chemical.co.jp/en/products/departments/mcc/emulsifier/product/1205874_8006.html Last access: April 2021 